\title{
NATURAL GAS PRICE ELASTICITIES AND \\ OPTIMAL COST RECOVERY UNDER CONSUMER HETEROGENEITY: EVIDENCE FROM 300 MILLION NATURAL GAS BILLS
}

\author{
Maximilian Auffhammer \\ Edward Rubin \\ Working Paper 24295 \\ http://www.nber.org/papers/w24295 \\ NATIONAL BUREAU OF ECONOMIC RESEARCH \\ 1050 Massachusetts Avenue \\ Cambridge, MA 02138 \\ February 2018
}

\begin{abstract}
We thank Reed Walker, Sofia Berto Villa-Boas, James Sallee, Solomon Hsiang, Meredith Fowlie, Lucas Davis, Severin Borenstein, Peter Berck, and seminar/workshop participants at Berkeley ARE, Cornell University, the Luleå Department of Economics, Yale University, Camp Resources, and the Heartland Environmental and Resource Economics Workshop for valuable feedback. Auffhammer gratefully acknowledges support from the Julian Simon Fellowship at Property and Environment Research Center (PERC). All remaining errors are the authors'. The views expressed herein are those of the authors and do not necessarily reflect the views of the National Bureau of Economic Research.
\end{abstract}

NBER working papers are circulated for discussion and comment purposes. They have not been peer-reviewed or been subject to the review by the NBER Board of Directors that accompanies official NBER publications.

(C) 2018 by Maximilian Auffhammer and Edward Rubin. All rights reserved. Short sections of text, not to exceed two paragraphs, may be quoted without explicit permission provided that full credit, including $\odot$ notice, is given to the source. 
Natural Gas Price Elasticities and Optimal Cost Recovery Under Consumer Heterogeneity:

Evidence from 300 million natural gas bills

Maximilian Auffhammer and Edward Rubin

NBER Working Paper No. 24295

February 2018

JEL No. O13,Q41

\begin{abstract}
$\underline{\text { ABSTRACT }}$
Half of American households heat their homes with natural gas furnaces and $43 \%$ use it to heat their water. Hence, understanding residential natural gas consumption behavior has become a first-order problem. In this paper, we provide the first ever causally identified, microdata-based estimates of residential natural gas demand elasticities using a panel of approximately 300 million bills in California. To overcome multiple sources of endogeneity, we employ a two-pronged empirical strategy: (1) we exploit a discontinuity along the border between two major natural-gas utilities in conjunction with (2) an instrumental variables strategy based upon the differences in the utilities' rules/behaviors for internalizing changes in the upstream natural gas spot market. We estimate that the elasticity of demand for residential natural gas is between -0.23 and -0.17 . We also provide evidence of significant seasonal and income-based heterogeneity in this elasticity. This heterogeneity suggests unexplored policy avenues that may be simultaneously efficiencyenhancing-in the absence of first best pricing - and pro-poor.
\end{abstract}

Maximilian Auffhammer

Agricultural and Resource Economics Department

University of California, Berkeley

207 Giannini Hall

Berkeley, CA 94720-3310

and NBER

auffhammer@berkeley.edu

Edward Rubin

Agricultural and Resource Economics Department

University of California, Berkeley

207 Giannini Hall

Berkeley, CA 94720-3310

edwardarubin@gmail.com 


\section{Introduction}

Coal dominated all other fossil fuels throughout the late $19^{\text {th }}$ and most of the $20^{\text {th }}$ centuries and powered unprecedented economic transformation in the United States and many other major economies. The recent arrival of a new technology enabling gas extraction from below the surface, hydraulic fracturing ("frac(k)ing"), is unearthing ample supplies of low-cost natural gas that will foreseeably fuel the first half of the 21st century. Fracking received significant exemptions from the Clean Air Act, the Clean Water Act, and the Safe Drinking Water Act via the Energy Policy Act of 2005 (Environmental Protection Agency 2013), potentially furthering the rise of natural gas within energy markets. Natural gas production in the United States has expanded dramatically, and natural gas prices have fallen considerably, often residing at half of their pre-2005 levels (Hausman and Kellogg 2015). In 2016, natural gas surpassed coal as the main source of energy for electricity generation in the United States and half of US residences used natural gas as their main heating fuel (U.S. Energy Information Administration 2016b). US residential consumers, depending on the severity of the winter, spend 50-80 billion dollars per year on natural gas (BLS, 2017). The average household spends about as much money on natural gas as it spends on water (BLS, 2017).

The low price and newly abundant volumes of natural gas, coupled with natural gas's status as the cleanest and most efficient fossil fuel (Levine, Carpenter, and Thapa 2014; National Academy of Sciences 2016), have prompted broad public and policy support for the use of this fuel both in end uses and in the generation of electricity. ${ }^{1}$ Such support partially stems from natural gas's low carbon content per BTU, leading some to refer to natural gas as a "bridge fuel," bridging society toward a future powered by largely carbon-free sources of renewable energy.

Natural gas is not without critics. The most common criticisms of current natural gas policy center on environmental degradation, including groundwater contamination, the possible triggering of small earthquakes, increases in air pollution, and higher incidence of accidents from the large number of trucks servicing fracking sites (Glanz 2009; Bao and Eaton 2016). More broadly, researchers have critiqued inefficient and potentially regressive pricing (and

\footnotetext{
${ }^{1}$ The fact that an increasingly large share of natural gas is produced in the United States also wins natural gas considerable political support (Levine, Carpenter, and Thapa 2014).
} 
regulatory) regimes used in the consumer-facing side of the industry (Borenstein and Davis 2012; Davis and Muehlegger 2010).

Despite its policy relevance, there is a relative dearth of (well) identified estimates for the own-price elasticity of the demand for natural gas. ${ }^{2}$ Specifically, we are unable to find any published research that pairs consumer-level data with appropriate identification strategies to causally estimate a price elasticity of demand for natural gas that carries a causal interpretation. Table 1 lists the past studies, the type of data used, and the resulting estimates of the own-price elasticity of demand. As Table 1 shows, past papers either estimate the elasticity of demand for residential natural gas using aggregated data (e.g., Hausman and Kellogg; Davis and Muehlegger) or using micro data with average prices (e.g., Alberini, Gans, and Velez-Lopez 2011; Meier and Rehdanz 2010). ${ }^{3}$ The majority of these papers do not attempt to deal with bias resulting from multiple sources of simultaneity, which we discuss below.

Research on the price elasticity of demand for natural gas faces two major challenges: insufficient data and multiple potential sources of endogeneity. Many of the available datasets aggregate households' consumption across both space and time. This aggregation-coupled with utilities' multi-tiered volumetric pricing regimes, income-based discounts, and fixed charges-makes it impossible for researchers to match consumers to the actual prices they face. Aggregation across customers and seasons also inhibits research into heterogeneity across consumers. Perhaps most importantly, research on the elasticity of demand for natural gas must also consider multiple potential sources of endogeneity. The first source of endogeneity is the classic simultaneity that stems from the fact that quantity and price result from the equilibrium in a system of equations. Unlike the electricity sector, for natural-gas customers' rates change on a monthly basis-updating as a function of gas wholesale prices paid by the retail utilities. The second source of endogeneity results from the fact that price is mechanically a function of quantity in a block-rate price regime. As a household's consump-

\footnotetext{
${ }^{2}$ Though several previous papers have offered estimates for the price elasticity of demand for residential natural gas, the existing natural-gas demand elasticity literature addressing these issues is sparse relative to that of the electricity literature (Rehdanz 2007). A cursory Google Scholar search returns approximately 148,000 results related to economics, elasticities, and electricity; equivalent searches for coal and gasoline return approximately 70,000 results each. A similar search for articles related to natural gas finds fewer than 40,000 results. (The authors performed these searches in January 2017.)

${ }^{3}$ The exception is Rehdanz, who uses a two-period sample from West Germany, where it appears average price equalled marginal price. Rehdanz does not, however, address the endogeneity of price.
} 
tion increases, its marginal price increases in discrete steps; consequently, average price also increases with consumption. Thus, a simple, unidentified regression of quantity on price will result in an incorrect-and potentially positive-estimate of the price elasticity of demand.

This paper is the first to address these aggregation and endogeneity issues so as to causally identify the elasticity of demand for residential natural gas. In order to overcome both the aggregation problem and the endogeneity issues due to increased block rate pricing, the paper uses a dataset of approximately 300 million residential natural gas bills in California and builds on Ito 2014 to exploit a spatial discontinuity based upon the boundary between the service areas of two large natural gas utilities.

The paper makes four concrete contributions to the literature on estimating price elasticities of demand. First, the natural gas market provides a unique setting with monthly pass-through of wholesale prices to consumers-a rate characteristic in electricity markets. To overcome the resulting endogeneity, we combine a spatial discontinuity with a supplyshifting instrumental variables (IV) approach. We instrument the utilities' consumer-facing prices with the weekly average spot price of natural gas at a major natural gas distribution hub in Louisiana (the Henry Hub). This instrument is valid, as we know the formula of how utilities pass-through the price (providing a strong first stage), and the price is determined prior to within-bill consumption (strengthening the exclusion restriction). Jointly, the spatial discontinuity and spot-price instrument isolate plausibly exogenous variation in residential natural gas prices between neighboring households due to the two utilities' differential passthrough of spot-market prices. In other words, as a result of this two-part empirical strategy, coupled with the rich set of fixed effects that our dataset allows, the identifying variation in the residential price of natural gas comes from (1) on which side of a long-established border between utility-owned natural gas networks the household is located, and (2) the subtly different pricing rules governing the two rate-of-return-earning utilities as they individually respond to price variation in the natural gas spot market.

Our second contribution builds upon the fact that we observe whether households are part of a low-income program that provides subsidized natural gas to households. We use this knowledge to estimate price elasticities by high- versus low-income households. Third, we observe billing at a roughly monthly frequency for the households in our sample, allowing 
us to estimate seasonal as well as income-/season-specific price elasticities. Finally, due both to the temporal resolution of the data and to the fact that we observe households over long periods of time in the same housing structure, we determine whether households respond to current or lagged prices. This result bears evidence on the salience of natural gas bills.

We find that on average, the price elasticity of demand for residential natural gas ranges from -0.23 to -0.17 . Importantly, we find evidence of heterogeneity in this elasticity along the dimensions of season and income. Both lower-income and higher-income households are essentially inelastic to price in summer months. However, in winter months, lowerincome households are substantially more elastic to price than higher-income households. We discuss unexplored policies with the potential to increase both efficiency and progressivity in settings where externalities from natural gas consumption are priced. Finally, we show evidence that households respond to lagged electricity prices-a result consistent with rational inattention following from the difficulties households face in finding real-time information on natural gas consumption and prices. In addition to motivating previously unexplored policies with the potential to enhance efficiency and reduce the burden on the poor, these heterogeneity findings also supply insights into other pooled elasticity estimates that do not consider heterogeneity.

\section{Institutional setting}

In order to identify a causal estimate of the price elasticity of natural gas demand, we need to explain the institutional and physical setup of the natural gas industry in the United States. This market is commonly divided into four segments: (1) production and processing, (2) transportation, (3) storage, and (4) local distribution companies (LDCs). Figure 1 illustrates the basic institutional organization of the natural gas industry. ${ }^{4}$ The four segments we discuss below roughly follow Figure 1 except that they exclude end users (those users who only consume natural gas) and the liquid natural gas import/export-based segments of the market. While this paper focuses on the behavior of residential natural gas consumers, part of our

\footnotetext{
${ }^{4}$ We include liquid natural gas (LNG) in the figure for completeness, but liquid natural gas does not play a large role in the natural gas market in the United States: LNG imports currently account for less than one percent of natural gas imports and accounted for three percent of imports at their peak in 2007 (Levine, Carpenter, and Thapa 2014). For this reason, we omit LNG for the rest of this paper.
} 
identification strategy relies upon a basic understanding of the wider industry, specifically in understanding which instruments may shift supply without affecting demand. After discussing these four segments, we then describe the multi-tier pricing structure employed by the two Californian natural gas utilities discussed in this paper.

\subsection{Market segments}

Production and processing Natural gas enters the market at the wellhead where it is produced and first sold (Brown and Yücel 1993). Some wells produce only natural gas, while other wells produce natural gas in addition to crude oil (Levine, Carpenter, and Thapa 2014). The raw product then moves from wellheads to processors. Processors remove impurities and separate the raw product into multiple commodities (separating "natural gas" from "natural gas liquids") (Levine, Carpenter, and Thapa 2014).

Transportation High-pressure pipelines transport processed natural gas from production and processing areas to both intermediate users (storage facilities, processors, LDCs) and final users (electricity generators, industrial users, commercial users, and residential users). Figure 2 maps this pipeline network for the continental United States. Private companies own and operate segments of the pipeline; these pipeline companies' rates are regulated at the state level and the national level (Levine, Carpenter, and Thapa 2014). Extensive spot markets and futures markets exist for natural gas. Louisiana's Henry Hub connects to 13 intrastate and interstate pipelines. The Henry Hub is the designated delivery point for the New York Mercantile Exchange's natural gas futures contracts and the Henry Hub price is generally regarded as a nationally relevant price (Levine, Carpenter, and Thapa 2014). Figure 3 depicts the Henry Hub spot price from 1997 through 2016. Transportation costs represent a substantial percentage of natural gas prices; according to Levine, Carpenter, and Thapa, in 2011-2012, 72 percent of consumers' average heating costs originated in "transmission and distribution charges". ${ }^{5}$ Thus, the natural gas transportation network creates a nationally integrated market and simultaneously contributes to a sizable portion of the

\footnotetext{
${ }^{5}$ Levine, Carpenter, and Thapa also note that in 2007-2008 "transmission and distribution charges" accounted for 41 percent of consumers' average heating costs. It is worth keeping in mind that consumers' average heating costs fell approximately 20 percent in this period.
} 
prices paid by natural gas end users.

Storage Storage plays a major role in several parts of the natural gas market, but all parties store mainly for the same reason: volatility within the market. Due to its major roles in heating and electricity production, natural gas demand is strongly driven by weather and can be unpredictable in the short run. To combat price volatility and to be able to meet peak demand, both local distribution companies and large natural gas consumers store gas underground (Levine, Carpenter, and Thapa 2014). Producers utilize storage to smooth production.

Local distribution companies Local distribution companies' primary function is distributing natural gas to their contracted end users-industrial, residential, and commercial consumers of natural gas. To accomplish this task, LDCs purchase natural gas through both spot markets and longer-term contracts. In addition, LDCs own and operate their own pipeline and storage networks. To cover the fixed costs involved in their pipelines, storage, and administration, LDCs often utilize a combination of two-part tariffs and multi-tiered pricing regimes-though some utilities fold all of their costs into their volumetric pricing. State utility commissions (e.g., the California Public Utilities Commission) regulate LDCs' price regimes, allowing the LDCs to earn a regulated rate of return (Brown and Yücel 1993; Davis and Muehlegger 2010; Levine, Carpenter, and Thapa 2014).

\subsection{Natural gas pricing in California}

The California Public Utilities Commission (CPUC) regulates both of the utilities from which we draw data in this paper: Pacific Gas and Electric Company (PG\&E) and Southern California Gas Company (SoCalGas). Because this paper analyzes residential natural gas consumers' responses to natural-gas retail prices, the most relevant regulations facing PG\&E and SoCalGas are CPUC's price and quantity regulations. In addition, the California Energy Commission (CEC) defines geographic climate zones (see Figure A1), which, in part, determine households' price schedules (California Energy Commission 2015, 2017). 
For PG\&E's and SoCalGas's residential consumers, a household's bill depends upon five elements: ${ }^{6}$

1. The two-tiered price schedule set by the utility

2. The total volume of natural gas consumed during the billing period

3. The season (summer or winter) in which the bill occurs

4. The climate zone into which the household's physical location falls

\section{The household's CARE (California Alternate Rates for Energy) status ${ }^{7}$}

Figure A2 provides an example of a typical residential natural gas bill from PG\&E.

Both PG\&E and SoCalGas utilize two-tiered pricing regimes. The California Energy Commission divides California into 16 climate zones in which households' needs for heating should be relatively homogeneous (California Energy Commission 2015, 2017; Pacific Gas and Electric Company 2016). The utilities also divide the year into heating (winter) and non-heating (summer) seasons. Based upon a household's climate zone (determined by the household's location) and the season, the CPUC determines a volume of natural gas that should be adequate for heating during the course of one day. This volume of natural gas is called the household's daily allowance. Multiplying the household's daily allowance by the number of days in the billing period gives the household's total allowance for the bill. For each unit $\left(\right.$ therm $^{8}$ ) of natural gas up to the bill's total allowance, the household pays the first tier's per-unit price (baseline price). For each unit of gas above the household's total allowance, the household pays the second tier's per-unit price (excess price). Figure 4a illustrates an example of the two-tier block-pricing regime used by PG\&E and SoCalGas. Figure 4b depicts how residential consumers' (daily) tier-one allowances vary through time within a given climate

\footnotetext{
${ }^{6}$ Consumers' billing periods do not perfectly align with calendar months. However, PG\&E's and SoCalGas's price changes do align with calendar months (during the years that our data cover). The two utilities deal with this misalignment of billing periods and price regimes slightly differently. PG\&E calculates individual bills for each calendar month under the assumption that consumption is constant throughout the billing period. SoCalGas calculates a single bill using time-weighted average prices (averaging across the different price regimes). These methods are equivalent under a single linear price but differ under the actual multi-tiered price regimes. Please see the Calculating bills section in the appendix for more detail.

${ }^{7}$ The previously mentioned program that provides subsidized energy rates to low-income households in California.

${ }^{8}$ The utilities in this paper work in units of volume called therms. One therm is equal to 100,000 Btu (U.S. Energy Information Administration 2016c).
} 
zone (PG\&E's climate zone $R$ and SoCalGas's climate zone 1). Figure A1 depicts California's 16 California Energy Commission (CEC) defined climate zones.

Each month, the utilities update their price schedules. The absolute difference between the first-tier price and the second-tier price also varies but tends to remain constant for several months. ${ }^{9}$ These monthly price changes allow the utilities to charge customers at rates that reflect the prevailing price of natural gas. In fact, the utilities tie their price updates to their costs-thus linking residential rates to spot market prices. ${ }^{10}$ If the utilities wish to change the way in which their prices are tied to market prices and other costs, they must receive authorization following a review process with CPUC. Figure 6a illustrates these monthly price-regime changes and the fairly fixed step between the two tiers. Figure 6b depicts the correlation between the utilities' baseline (first-tier) prices and the spot market price of natural gas at the Henry Hub.

A household's participation in the CARE (California Alternate Rates for Energy) program also affects the prices that the household faces. Households qualify for CARE by either meeting low-income qualifications or receiving benefits from one of several state or federal assistance programs (e.g., Medi-Cal or the National School Lunch Program) (Southern California Gas Company 2016). CARE prices are 80 percent of standard prices at both tiers. In addition to giving us the household's correct pricing regime, we use CARE status to identify low-income households.

\section{Data}

\subsection{Natural gas billing data}

The billing data in this paper come from two major utilities in California: Pacific Gas and Electric Company (PG\&E) and Southern California Gas Company (SoCalGas). The PG\&E data cover residential natural gas bills in PG\&E's territory from January 2003 through December 2014. The SoCalGas data cover residential natural gas bills from May 2010 through September 2015. Thus, the two utilities' data overlap from May 2010 through December 2014. After

\footnotetext{
${ }^{9}$ The utilities differ in the frequencies at which which they change this absolute difference: PG\&E adjusts the distance between the two tiers' price much more frequently than SoCalGas.

${ }^{10}$ The utilities report their weighted average costs of gas to the CPUC.
} 
excluding zip codes with fewer than 50 households, PG\&E's service area covers 597 5-digit zip codes $(680,846$ 9-digit zip codes) with a total of 5,888,276 households and 180,663,705 bills. After excluding zip codes with fewer than 50 households, SoCalGas's service area covers 611 5-digit zip codes (610,207 9-digit zip codes) with a total of 2,526,503 households and 95,335,393 bills. The left side of Figure 5 depicts PG\&E's and SoCalGas's service areas at the 5-digit zip code level. Table 2 provides a brief summary of the billing data with regard to the numbers of bills, households, zip codes, and monetary values of the bills. Tables 2 and 3 summarize prices, quantities, and other variables of interest-pooling across all observations and also splitting the data by season or CARE status. Both tables summarize the full datasetall zip codes across both utilities-and a subset of the data based upon all 5-digit zip codes served by both utilities. We describe this subset in detail below in the Empirical strategy section.

The utilities' billing data are at the household-bill level: a single row of the dataset represents a single billing period for a given household. Table A17 describes the variables (columns) in this dataset. We follow the natural gas utilities' convention in defining a household (or customer) as the interaction between a unique utility account and a unique physical location identifier.

We also utilize historical data on pricing from the two utilities. As described above, these pricing data include (1) each utility's monthly two-tier pricing regime and (2) the daily allowance for each climate zone during each season. After joining these pricing data to the households' billing data, we are able to determine both the marginal price and average price (and average marginal price) for each bill received by each household. We forgo analyses below the five-digit zip code because (1) many households are missing their full 9-digit zip codes (the plus-four codes are missing), (2) many of the 9-digit zip codes do not match into ZIP4 databases, and (3) our identification strategy already utilizes within-zip-code variation (discussed in detail below).

\subsection{Weather data}

Data on daily weather observations originate from the PRISM project at Oregon State Univer- 
sity (PRISM Climate Group 2004). We match this local, daily weather data to the household consumption data at the day by 5-digit-zip-code level. The PRISM dataset contains daily gridded maximum and minimum temperature for the continental United States at a grid cell resolution of roughly 2.5 miles $(4 \mathrm{~km})$. Figure A3 maps a single day of average temperature from the PRISM data for the continental United States. We observe these daily data for California from 1980-2015. In order to match the weather grids to zip codes, we obtained a GIS layer of zip codes from ESRI (Esri 2017), which is based on US Postal Service delivery routes for 2013. For small zip codes not identified by the shape file, we purchased the location of these zip codes from a private vendor ${ }^{11}$. We matched the PRISM grids to the zip code shapes and averaged the daily temperature data across multiple grids within each zip code for each day. For zip codes identified as a point, we use the daily weather observation in the grid at that point. This exercise results in a complete daily record of minimum and maximum temperatures_as well as precipitation—at the zip-code level from 1980-2015.

\section{Empirical strategy}

In this section we describe the empirical strategy that we use to identify the price elasticity of demand for residential natural gas consumers. First, we present the basic estimating equation that motivates the paper's results. Next, we discuss the inherent challenges to identification in this setting. We then discuss potential solutions to these challenges and detail which of these solutions are feasible in this paper's specific setting. Finally, before moving to the results, we provide evidence for the validity of the instruments.

\subsection{Estimating equation}

The relationship at the heart of this paper's elasticity estimates is

$$
\log \left(q_{i, t}\right)=\eta \log \left(p_{i, t}\right)+\lambda_{i, t}+\varepsilon_{i, t}
$$

\footnotetext{
${ }^{11}$ zip-codes.com
} 
where $i$ and $t$ index household and time; $q$ denotes quantity demanded; and $p$ denotes price. Rather than choosing a specific type of price, we present results for five variants of price. These five types of price include the price that classical economic theory deems relevant-the marginal price-in addition to average price, average marginal price, baseline (first-tier) price, and simulated marginal price (defined and discussed below). ${ }^{12}$ In the results section, we also discuss which lag of price is most salient to consumers (see Figure 7 for an example and a brief discussion of price lags). The term $\lambda_{i, t}$ represents household fixed effects, time-based fixed effects, and/or household-by-time fixed effects-depending on the specification. Our main specification in this paper uses household fixed effects and city by month-of-sample fixed effects (e.g., Fresno in January 2010; also called city by year by month). A causally identified estimate of $\eta$ yields the own-price elasticity of demand.

\subsection{Challenges to identification}

Two main sources of endogeneity threaten identification in equation 1.

The first challenge in identifying this own-price elasticity of demand is the potential endogeneity that results from the simultaneous determination of price and quantity that results from the equilibrium of supply and demand-simultaneity (e.g., Woolridge 2009). In the presence of simultaneity, standard ordinary least squares (OLS) fails to properly treat the endogeneity inherent in (1). As discussed above, many papers in the natural gas literature ignore this potential source of bias while estimating the price elasticity of demand-relying upon fixed effects, uncorrelated demand and supply shocks, and/or assumptions of exogenous prices. If simultaneity is indeed present in this setting, then the estimates in these papers will recover biased estimates for the elasticity of demand for residential natural gas.

A second challenge to identification in this paper results from our paper's specific context: the two-tiered price schedule within California's natural gas market. Put simply, in tiered pricing regimes, the marginal price is a (weakly increasing, monotonic) function of quantity. For the same reason, average price is also a function of quantity. Thus, when a household consumes more, its marginal and average prices mechanically increase. In terms of identifying

\footnotetext{
${ }^{12}$ We define average marginal price as the quantity-weighted marginal price paid by a customer during her billing period. Average marginal price does not include fixed charges, while average price does.
} 
the price elasticity of demand, this is bad variation: the marginal price that a household faces is endogenous because the marginal price is correlated with unobserved demand shocks (Ito 2014). This bias is a specific form of simultaneity often called reverse causality.

In practice, one generally cannot sign the bias resulting from the classical simultaneity of price and quantity without making further assumptions regarding the correlation of supply and demand shocks. On the other hand, the bias resulting from marginal and average prices being a function of quantity results in upwardly biased estimates of demand elasticities. In extreme cases, this latter case of bias can yield estimates that suggest upward-sloping demand curves.

Table 5 demonstrates the consequences of failing to address these challenges to identification by estimating the price elasticity of demand $-\eta$ in equation 1 via ordinary least squares (OLS) using marginal price (columns 1-3) and baseline (first-tier) price (columns 4-6). We also vary the set of controls for each price. For a given price, the leftmost columns apply the simplest set of controls. The "identification strategy" presented in Table 5 makes no attempt to correct for the aforementioned potential biases outside of a fairly rich set of fixed effectshousehold fixed effects and city by month-of-sample fixed effects. Each regression controls for within-bill heating degree days (HDDs) during the billing period. ${ }^{13}$ The leftmost column for each price uses a five percent sample of all bills from PG\&E and SoCalGas (sampled at the fivedigit zip code). The remaining columns (columns 2, 3, 4, and 5) use a border-discontinuity motivated sample in which we keep all zip codes where the zip code receives natural gas from both PG\&E and SoCalGas (discussed in detail below; also see Figure 5). The leftmost and center columns for each price control for household fixed effects and month-of-sample fixed effects. The rightmost columns for each price control for city by month-of-sample fixed effects (e.g., Fresno in January 2010).

The six regressions in Table 5 employ two different measures of price: (1) the household's marginal price during the relevant billing period, and (2) the household's baseline (first-tier) price during the relevant billing period. These two-rather related ${ }^{14}$-measures of price yield

\footnotetext{
${ }^{13}$ The number of heating degrees in a day is equal to the difference between the day's average temperature and 65. Days with average temperatures above $65^{\circ} \mathrm{F}$ receive zero heating degrees. More formally, we calculate the number of heating degrees for day $t$ with mean temperature $\bar{T}_{t}$ (in ${ }^{\circ} \mathrm{F}$ ) as $\operatorname{HDD}_{t}=\mathbb{1}\left\{\bar{T}_{t}<65\right\} \times\left(65-\bar{T}_{t}\right)$. The HDDs variable above is thus HDDS $=\sum_{t} \mathrm{HDD}_{t} / 1000$.

${ }^{14}$ The correlation between marginal price and baseline price is approximately 0.79 ; see Table A1 for bivariate
} 
considerably different results, differing both quantitatively and qualitatively. The baseline price suggests an elasticity between -0.10 to 0.02 , while the marginal price indicates a positive demand elasticity between 0.43 and 0.47 . The substantial differences across estimates in Table 5 suggest at least one of the aforementioned biases are present. Specifically, the fact that the marginal-price based elasticity estimates are positive (implying upward-sloping demand curves), while the baseline-price based estimates are negative, suggests that the priceis-a-function-of-quantity flavor of simultaneity is a first-order problem in this context. This interpretation follows from the results due to the fact that baseline prices are not a function of quantity, while marginal prices are a function of quantity.

While the baseline-price based elasticity estimates appear to be reasonable in terms of magnitude, they are still not identified, as them still may suffer from simultaneity bias. Simply adding more observations in the flavor of the big data movement does not address this potential endogeneity: column 4 of Table 5 does not appear any more plausible than columns 5 or 6 , despite adding more than 7 million observations-the same can be said for column 1 vs. columns 2 and 3. In addition, the fact that the baseline-price based estimates change sign and magnitude when we move from the 5\% CA sample (column 4) to the border-discontinuity motivated sample (columns 5 and 6) provides some evidence that classical simultaneity may be present. In this border-discontinuity motivated sample, within-zip code price variation comes from utilities' differentially pricing natural gas over a set of potentially comparable households. However, whether the change in coefficients is due to removing endogenous variation or due to changes in the sample, the existence of simultaneity is fundamentally a statistically untestable issue which stems from the theoretical setup of how market prices originate. Rather than assuming that the sample and/or fixed effects remedy the problem, we instead present a multipart empirical strategy to directly resolve the challenge.

Finally, it is worth noting that the baseline-price based elasticity estimates are well within the range of estimates from the existing literature, as shown in Table 1. This outcome warrants some concern, as it suggests that some of these estimates may suffer from endogeneity.

correlations of prices measures. 


\subsection{Solutions for identification}

Having shown that OLS with fixed effects and extensive data does not cleanly identify the own-price elasticity of demand in this setting, we now discuss several potential routes for identifying the causal effect of price on quantity in our setting. In the end, we opt for an identification strategy that interacts a spatial discontinuity with an instrumental variables approach.

\subsubsection{Discontinuities}

A common route toward identification in applied microeconomics involves finding relatively small geographic units that receive different prices within the same time period. The assumption is that observable and unobservable characteristics and, more importantly, households' price responsiveness do not differ across the border, yet they are exposed to different prices changes allowing for econometric identification. Arbitrary administrative boundaries that determine policies' catchment areas provide a popular tool in this context, e.g., Dell 2010; Chen et al. 2013; Ito 2014. In our context of natural gas in California, the boundary between PG\&E and SoCalGas offers potentially arbitrary within-city (and within-zip code) variation in prices during a month. Specifically, the boundary between PG\&E's and SoCalGas's natural gas service areas bisects eleven cities-in three clusters-in southern California: Arvin, Bakersfield, Fellows, Fresno, Del Ray, Fowler, Paso Robles, Selma, Taft, Tehachapi, and Templeton. The left panel of Figure 5 displays the two utilities' service areas throughout California (for zip codes sufficiently covered in the datasets). The right panel of Figure 5 zooms in on the eleven cities (39 zip codes) that PG\&E and SoCalGas both serve. Within these eleven cities, PG\&E serves all 39 zip codes, while SoCalGas serves 18 of the zip codes.

This identification strategy rests upon the assumption that households on one side of the utilities' border provide a valid control group for households on the other side of the border. Because the boundary mainly represents the extent of each utilities' underground distribution network and is unlikely to enter into households' preferences, the exogeneity of the boundary to household characteristics should be valid (Ito 2014). The main threat to this identification strategy is that utilities' networks correlate with geographic or neighborhood 
characteristics over which individuals have preferences. However, we use household fixed effects, which absorb mean differences across households. Thus, for the border discontinuity to be invalid, households would have to sort in a way consistent with their elasticities, and the utilities' price series would have to differ significantly in their variances. Because the data contain considerable variation in prices for both utilities and the panel contains approximately six years of monthly bills, this sort of sorting bias seems unlikely. Figure 6b suggests the generating distributions for the utilities' prices are quite similar (the standard deviations of the price series are 0.0940 and 0.1053 for PG\&E and SoCalGas, respectively). In addition, Table 4 provides some limited evidence ${ }^{15}$ of balance across the utility border, comparing PG\&E and SoCalGas households within season (summer or winter) and within income group. Within a season-income group, the utilities' customers appear to consume similar volumes of natural gas, receive similar numbers of days per bill, receive similar allowances on the first tier, and face similar numbers of heating degree days. SoCalGas customers tend to receive slightly lower bills, but the difference is less than half of one standard deviation of total bill amount.

Ito 2014 employs a similar strategy within the context of electricity consumption. However, there is at least one significant difference between the electricity and natural gas contexts which prevents us from entirely adopting Ito's identification strategy: discontinuities within electricity utilities' seven-tier pricing regime. By law, the electricity utilities in Ito's study are not allowed to move the price of the first two tiers-they must recover changes in their costs by moving tiers three through seven. In addition, electricity utilities in California do not generally change consumer's prices each month-and prices do not change across all utilities at the same time. Thus, marginal prices in Ito's setting move differently depending upon a household's tier and utility. Ito argues that the residual variation-combining the spatial discontinuity with this pricing discontinuity and spatiotemporal fixed effects-is plausibly exogenous from demand shocks. Because natural gas (in California) has only two tiers and because the absolute difference between the two tiers has relatively low variation, we are unable to take advantage of price-tier based discontinuities. Therefore, in addition to this utility-border-based discontinuity, we adopt an additional strategy to overcome endogeneity.

\footnotetext{
${ }^{15}$ Our data on households is restricted to information from natural gas bills.
} 


\subsubsection{Instrumental variables}

The second element in our empirical strategy for identifying the price elasticity of demand for natural gas involves a traditional solution to simultaneity: supply-shifting instruments. In this context, the ideal supply-shifting instrument is (1) strongly correlated with the prices that the natural gas utilities charge their customers (the first stage), and (2) uncorrelated with residual shocks affecting consumers' demand (Angrist and Pischke 2009). In this paper, our instrument is the Henry Hub spot price for natural gas.

Henry Hub spot price Specifically, we instrument the prices that consumers face (e.g. marginal price, average price, baseline price) with the average spot price at Louisiana's Henry Hub in the week preceding the change in prices. We also interact the Henry Hub spot price with utility to allow the utilities to differentially pass through price changes. The Henry Hub spot price represents the nationally prevailing price for short-term natural gas contracts (the hub sits at the intersection of 13 intrastate and interstate pipelines) (U.S. Energy Information Administration 2016a). This instrument mechanically satisfies the requirement of having a strong first stage, as both utilities base their prices, in part, on market prices for natural gas in the period preceding their rate changes-the utilities buy natural gas on the spot market, and the California Public Utilities Commission regulates how the utilities fold their costs into the price regimes that customers face on a monthly basis.

The exclusion restriction for this spot-price based instrument is less obvious, but several factors suggest the exclusion restriction is plausibly valid. First, California's entire residential natural gas demand represents at most three percent of national natural gas consumptionlimiting the individual utilities' ability to set/influence spot prices and the Henry Hub. Second, we interact the spot price instrument with utility. This interaction, conditional on city by month-of-sample fixed effects, implies that the identifying variation in our instruments comes from the difference in how the two utilities' incorporate monthly spot-price shocks into their pricing regimes. Third, because the utilities must obtain approval for price changes before the new price regime begins, the spot price is temporally disconnected from the billing period. In other word, the utilities' costs (and approved prices) are based upon spot prices that 
precede the billing period by several weeks. Thus, shocks that affect the Henry Hub spot price are distinct in time from shocks that affect natural gas demand-our fixed effects will absorb any of these shocks, so long as they do not differ across the utilities' border within a month. Additionally, we show that the most salient lag of price is likely the second lag of price, further disconnecting contemporaneous local demand shocks from market-level supply shocks two months prior. We also control for the number of heating degree days (HDDs) in the household's zip code during the households' billing period. Because residential consumers primarily use natural gas in heating applications, controlling for HDDs further reduces the opportunity for local demand shock to affect national prices. Therefore, we argue that the exclusion restriction is plausibly valid for our spot-price instrument.

Our identification strategy thus interacts the spatial discontinuity between PG\&E's and SoCalGas's service areas with the Henry Hub spot price. Specifically, the identifying variation stems from the two utilities' divergent pass-through of the spot market price-differentially projecting variation in the the natural gas spot market across a tenably arbitrary border between the two utilities.

By employing a two-part identification strategy that interacts a spatial discontinuity with a price instrument, we avoid weaknesses inherent in either individual identification strategy. For instance, simply instrumenting residential prices with the spot-market price may not entirely purge the endogenous, bad variation from residential prices, as variation in the spot market likely results from both supply and demand shocks. Our identification strategy instead takes variation from the spot market and projects it across the utilities' border, treating neighboring households with prices that differ only due to which utility provides natural gas. Additionally, our identification strategy also allows repeated "treatments" across the discontinuity, as the utilities change residential natural gas prices each month. This repetition of treatment both increases power and diminishes concerns regarding sorting, as both sides of the border will be "treated" over time. Thus, we contend this two-part identification strategy is well-suited for the challenges to identification in this setting. 
Spot price IV, first stage Panel A of Table 6 provides the first-stage estimates for the twostage least squares (2SLS) equations

$$
\begin{aligned}
& \log \left(p_{i, t}\right)=\pi_{1 a} p_{i, t}^{\mathrm{spot}}+\pi_{1 b} p_{i, t}^{\mathrm{spot}} \times \mathrm{SCG}_{i}+\pi_{2} \mathrm{HDD}_{i, t}^{\text {bill }}+\mathrm{HH}_{i}+\mathrm{City}_{i, t}+u_{i, t} \\
& \log \left(q_{i, t}\right)=\eta_{1} \log \left(p_{i, t}\right)+\eta_{2} \mathrm{HDD}_{i, t}^{\text {bill }}+\mathrm{HH}_{i}+\mathrm{City}_{i, t}+v_{i, t}
\end{aligned}
$$

where $\mathrm{HH}_{i}$ is a household fixed effect, City ${ }_{i, t}$ is a city by month-of-sample fixed effect, $\mathrm{SCG}_{i}$ is an indicator for whether the household's retail utility is SoCalGas, and $\operatorname{HDD}_{i, t}^{\text {bill }}$ is the number of heating degree days for household $i$ during its billing period that began in month $t$.

The spot-price by utility term is not collinear with the city by month-of-sample fixed effects because households' bills do not perfectly align with calendar months: consequently, the bills span multiple price regimes (see Figure 7). In a bill that spans two calendar months, the household receives a weighted average of the two months' price regimes. To instrument these weighted averages of prices, we calculate corresponding weighted averages of the relevant spot prices by weighting the months' relevant spot prices by their temporal share of the bill. ${ }^{16}$

Figure $6 \mathrm{~b}$ provides visual evidence of the first stage-illustrating (1) the link between the two utilities' prices and the Henry Hub spot price and (2) the utilities' differential responses to the spot price. Throughout the rest of the paper, we define the Henry Hub spot price as the average spot price for natural gas at the Henry Hub during the seven days preceding the utility's change in pricing.

Panel A of Table 6 displays the first-stage results for equation 2 using five different prices that may be relevant to households: marginal price, average price, average marginal price, baseline price, and simulated marginal price ${ }^{17}$ (using the log of each price). Each price is the second lag of the contemporaneous price. ${ }^{18}$ Table 7 and Tables A3-A7 compare consumers' varying responses to different lags of price.

Both Figure $6 \mathrm{~b}$ and Panel A of Table 6 demonstrate that the spot-price based instruments are quite strong: the $F$ statistics testing the joint significance of the instruments range from

\footnotetext{
${ }^{16}$ See the appendix section Calculating bills for further discussion of bills spanning multiple months.

${ }^{17}$ Simulated marginal price refers to a simulated instrument for marginal price. We discuss this measure of price in the next section.

${ }^{18}$ The current bill is lag zero, the prior bill contains the first lag of price, and the bill preceding the prior bill contains the second lag of price.
} 
369.9 to $1,333.2$. This significance is unsurprising, because the utilities purchase gas on the spot market and incorporate these costs directly into their price regimes. The significance of the interaction between spot price and utility (SoCalGas) in the second row of Panel A in Table 6 confirms that the utilities differ appreciably in incorporating spot-market costs into their pricing regimes: PG\&E's pricing regime appears to be much less responsive to the contemporaneous spot price than that of SoCalGas. ${ }^{19}$ Though the city by month-of-sample fixed effect should control for most local demand shocks, bills do not perfectly match months. The within-bill HDDs variable $\mathrm{HDD}_{i, t}^{\text {bill }}$ in equation 2 controls for any remaining weatherbased demand shocks. The results in Table A10 demonstrate robustness to excluding (oddnumbered columns) or including (even-numbered columns) within-bill heating degree days, which suggests that the instrument is exogenous to local weather shocks, one of the key localdemand drivers in natural gas (Davis and Muehlegger 2010; Levine, Carpenter, and Thapa 2014; Hausman and Kellogg 2015).

While the first stage is quite strong for all specifications, the results in Panel A of Table 6 suggest the instrument is strongest—in terms of first-stage significance-for baseline price, followed by average marginal price, average price, marginal price, and finally simulated marginal price. A likely reason for this outcome is that baseline price is the least noisy price: it is the only price that is not a function of the consumer's quantity, and it does not include variation from changes in the size of the step between the two tiers' prices. By these terms, (simulated) marginal price is the noisiest, which is consistent with marginal price having the smallest first-stage $F$ statistic of the five prices. $^{20}$

\subsubsection{Instrumented prices and simulated instruments}

In the preceding sections, we discussed how we interact a spot-price-pass-through based instrument with a spatial discontinuity in utilities' service areas to overcome bias stemming from the classic form of simultaneity-i.e., quantity and price (our dependent and independent variables) result from a simultaneously determined equilibrium. We now discuss the aspect

\footnotetext{
${ }^{19}$ One difference between the utilities' pricing regimes is that PG\&E does not have a fixed charge, while SoCalGas does. Thus, PG\&E recovers both fixed and volumetric costs through volumetric charges to its customers.

${ }^{20}$ Although the first-stage estimates in Panel A of Table 6 have the flavor of pass-through results, one should keep in mind that equation 2 specifies a log-linear form (logged price as the response variable), which does estimate pass-through.
} 
of our identification strategy that deals with the price-is-a-function-of-quantity endogeneity present in multi-tiered pricing contexts. ${ }^{21}$ We present three separate options for breaking this endogenous link between price and quantity, but, in the end, the options yield very similar results.

Option 1: Instrumented prices One method for breaking the endogenous link between a household's price and its quantity is simply to instrument the household's price with a variable that is aggregated at a unit above household. Consider the IV strategy discussed above: instrumenting a household's price with the Henry Hub spot price interacted with utility. Because this instrument only varies at the level of billing-period by utility, when we regress a household's endogenous price on this instrument (and our set of fixed effects) in the first stage, the variation captured by the predicted prices is only the variation that correlates with the spot price, which is determined weeks, if not months, before the household's consumption decision. Thus, if the spot price provides a valid instrument in the classical simultaneity context, it also provides a valid instrument for the second price-is-a-function-of-quantity endogeneity.

Option 2: Baseline price In a similar manner, the baseline price provides a valid instrument that breaks the price-is-a-function-of-quantity endogeneity. Because a household's baseline price is not a function of its quantity consumed, baseline price does not suffer from the same endogeneity. Baseline price is also strongly predictive of marginal (or average) price. ${ }^{22}$ Thus, in application, one could either replace marginal (or average) price with baseline price or instrument one of the endogenous prices with baseline price. There is at least one drawback to this approach: baseline price, by definition, fails to capture the higher price that a household faces when the household exceeds its total monthly allowance.

Option 3: Simulated instrument Simulated instruments ${ }^{23}$ provide a third option for breaking the price-is-a-function-of-quantity flavor of endogeneity. The simulated-instrument ap-

\footnotetext{
${ }^{21}$ This endogeneity is present in marginal price, average price, and average marginal price-all three prices are functions of the individual household's quantity consumed.

${ }^{22}$ The correlation between baseline price and marginal price is approximately 0.79 ; the correlation between baseline price and average price is approximately 0.94. See Table A1 for all bivariate correlations between our five measures of price.

${ }^{23}$ Also called policy-induced instruments.
} 
proach follows a methodology suggested in Ito 2014. Specifically, this approach creates an instrument (or proxy) for marginal (or average) price by plugging a lagged level of consumption into the current price regime, i.e.,

$$
z_{i, t}=p_{i, t}\left(q_{t-k}\right)
$$

The main idea for this instrument is using a household's consumption history to predict whether a household will face the baseline or excess price in the current period. As with any instrument, we want to accomplish this prediction in a way that is strongly predictive of the true outcome (the first stage) and that is uncorrelated with any recent shocks to the household (the exclusion restriction) (Angrist and Pischke 2009). For these reasons, we modify equation 4 slightly. First, we use the households' lagged consumption levels (from lagged bills 10 through 14 months prior) to calculate the share of lagged periods that exceed this billing period's baseline allowance, i.e.,

$$
s_{i, t}=\frac{1}{5} \sum_{k=10}^{14} \mathbb{1}\left\{q_{i, t-k}>\bar{A}_{i, t}\right\}
$$

where $\bar{A}_{i, t}$ is household $i$ 's baseline allowance in time (bill) $t$. We then calculate the simulated instrument for marginal price, $z_{i, t}$, as

$$
z_{i, t}=\mathbb{1}\left\{s_{i, t} \leq 0.5\right\} \times p_{i, t}^{\text {base }}+\mathbb{1}\left\{s_{i, t}>0.5\right\} \times p_{i, t}^{\text {excess }}
$$

Summarizing equations 5 and 6: this simulated instrument for marginal price predicts that a household will exceed its allowance when the majority of the household's past bills (using lagged months 10 through 14) exceed the current bill's allowance. ${ }^{24}$

Table A2 provides evidence that this simulated-instrument approach significantly predicts households' marginal prices. Specifically, Table A2 provides the estimate and standard error

\footnotetext{
${ }^{24}$ This simulated instrument is robust to the choice of months 10 through 14 . The goal is to keep the instrument in the same season as the current bill (maintaining a strong first stage), while allowing some temporal distance between the lags and the current period (the exclusion restriction: preventing short- and medium-run shocks from affecting both periods).
} 
for $\beta$ in the equation

$$
p_{i, t}^{\mathrm{mrg}}=\beta p_{i, t}^{\mathrm{sim}}+\mathrm{HH}_{i}+\mathrm{City}_{i, t}+w_{i, t}
$$

where $p_{i, t}^{\mathrm{mrg}}$ is household $i$ 's marginal price in time $t$ and $p_{i, t}^{\mathrm{sim}}$ is our simulated instrument for household $i$ 's marginal price in time $t$ (i.e., $p_{i, t}^{\mathrm{mrg}}$ ). The estimates for $\beta$ in Table A2 confirm the strong "first stage" for this simulated instrument. Marginal price and simulated marginal price are strongly and significantly correlated-both $t$ statistics are approximately 148 . The two columns in Table A2 also provide evidence of the robustness of the simulated instrument to the choice of lags: the estimates using lags 10-14 or 11-13 are virtually indistinguishable. In addition, the bottom row of Table A1 demonstrates that this simulated instrument is strongly correlated with marginal price $(r \approx 0.85)$ in addition to the other four measures of price.

Column 5 of Table 6 (Panel A) provides the first-stage results consistent with equation 2 but with the simulated instrument of marginal price substituted (proxying) for actual marginal price (and still instrumenting with spot price interacted with utility across the utilities' border). ${ }^{25}$ The first stage is again quite strong in this specification, and the results are qualitatively similar to the results in columns 1-4 of Table 6, Panel A. Henceforth we will refer to the simulated instrument for marginal price as simulated marginal price.

All subsequent results apply our two-part identification strategy which exploits the utilities' differential pass-through of spot-market prices to obtain exogenous variation in residential natural gas prices across the border between the two utilities' service areas. To incorporate the three competing options discussed immediately above, we provide results consistent each the strategies: instrumenting with spot price interacted with utility, proxying with baseline price, and employing simulated marginal price (the simulated instrument/proxy for marginal price). We now turn to our main results.

\section{Results}

In this section, we discuss the estimated price elasticities, using the empirical strategies extensively discussed in the preceding section. After presenting the main results for the

\footnotetext{
${ }^{25}$ It is worth noting that, in this paper, any result using the simulated instrument will have fewer observations than other results, as the simulated instrument is greedier for data-for an observation to remain in the dataset, its $14^{\text {th }}$ lag must also be in the dataset. Our other price measures are not as greedy.
} 
pooled elasticity (no heterogeneity), we examine whether households' price responses (i.e., elasticities) vary by season and/or by income.

\subsection{Pooled price elasticity of demand for natural gas}

Panel B of Table 6 displays the elasticity results from the second-stage regression specified in equation 3. These results instrument log price with the Henry Hub spot price (interacted with utility), exploit the spatial discontinuity, and use the log of daily average consumption (in therms) as the outcome. The five columns each estimate the elasticity using the log of a different type of price: marginal price, average price, average marginal price, baseline price, and simulated marginal price. As discussed above, each price is the second lag of price, as opposed to the contemporaneous price. The estimates for the price elasticity of demand range from -0.17 (simulated marginal price) to -0.23 (average price).

Panel B of Table 6 indicates that the estimated elasticity is fairly robust to the type of price. Table A11 demonstrates that the estimated elasticity is also robust to the inclusion/exclusion of heating degree days and to the levels of fixed effects - ranging from city by month-of-sample fixed effects to zip-code by week-of-sample fixed effects (while still including household fixed effects). The robustness to type of price also demonstrates robustness to how we control for the price-is-a-function-of-quantity endogeneity discussed above. Tables A11-A15 demonstrate the robustness of the estimated elasticity to excluding within-bill heating degree days and varying the spatiotemporal fixed effects. Finally, Table A16 contains marginal-price based elasticity estimates as we incrementally extend the study-area. Beginning with the study area (Common Zips), we add the zip codes neighboring (bordering) the study area (Neighbors 1); we then add the neighbors of the neighbors (Neighbors 2); last, we add a third band of neighbors (Neighbors 3). Figure A4 illustrates these groups of neighboring zip codes. The estimated elasticity from the first group of neighbors $(-0.19$ (0.05) in column 2 of Table A16) is quite close to the elasticity previously discussed $(-0.21,(0.07)$ in column 1$)$; the elasticities that include the second and third peripheral neighbors diminish in magnitude $(-0.12$ and $-0.09)$ but still differ significantly from zero.

Compared to their OLS-based counterparts in Table 5, the marginal-price based 2SLS 
estimates for the elasticity of demand now have opposite-and theoretically correct—signs. The magnitudes of the 2SLS estimates of the elasticity (approximately -0.20 ) are theoretically reasonable and within the range of previous findings. Furthermore, these estimates are plausibly identified and utilize consumers' actual prices.

As discussed above, the results discussed up to this point-e.g., the results in Table 6estimate the price elasticity of demand for residential natural gas using the second lag of the various prices. In order for a household to know the prices of its contemporaneous bill, the household would need to closely follow the approved advice letters published online by the utility or the California Public Utilities Commission. Otherwise, the household will learn about prices from past bills-hence the use of lagged prices. Because a household will not receive the bill for the previous billing period for several days into its current billing periodand because the household may not view the previous bill until it pays the bill (or its credit card bill, if the household uses automatic bill payment) weeks later-the household may not know the prices from its immediately previous bill until the current period is nearly over. For these reasons, it is plausible that the second lag of price is the most salient price to many households. Figure 7 illustrates an example of the timing for bill delivery, bill payment, and the relevant lags of prices.

Table 7 replicates the second-stage results for marginal price and average price but varies the lag/lead of price: beginning with the first lead of price, followed by contemporaneous price, the first lag of price, and finally the second lag of price. Tables A3-A7 provide further detail, varying the lead/lag of each of the five prices-ranging from the first lead of price to the third lag of price. Across the five types of measures of price, none of the first leads of price, contemporaneous prices, or first lags of price differ significantly from zero. For each type of price, both the second and third lags of price differ significantly from zero. For each price, the second-lag based elasticity slightly exceeds the third-lag based elasticity in magnitude, but the difference does not exceed the standard error. These results are consistent with households responding to two-to-three lags of price-as opposed to contemporaneous price-suggesting some degree of inattention by the household to the true price, akin to previous work on inattention and salience, e.g., Chetty, Looney, and Kroft 2009; Sallee 2013; Allcott and Taubinsky 2015. 


\subsection{Heterogeneity}

We now examine evidence of heterogeneity in the price elasticity of demand for natural gas. The institutional setting of this paper motivates two relevant dimensions of heterogeneityincome level and season-as the CPUC and utilities already apply different price regimes to households depending upon (1) the season of year (summer vs. winter) and (2) the household's income level (specifically, CARE status). If heterogeneity exists, then the regressions in the preceding section pool across the heterogeneous effects. This pooled parameter estimate may still be relevant for policy applications_-particularly for policies that cannot differentiate between seasons and/or income groups. However, because OLS weights heterogeneous treatment effects by their shares of the residual variation in the variable of interest-which is itself a function of (1) the numbers of observations in the heterogeneous groups and (2) the (residual) within-group variance in the variable of interest (Solon, Haider, and Wooldridge 2015)—one might wonder whether the pooled estimator always provides a policy-relevant estimate. In addition, in the presence of heterogeneous elasticities, policymakers can increase efficiency by integrating these (known) heterogeneities (Ramsey 1927; Boiteux 1971; Davis and Muehlegger 2010).

For income-based heterogeneity, we use a household's CARE status as a proxy for its income level. ${ }^{26}$ As discussed above, households qualify for CARE by either meeting low-income qualifications or by receiving benefits from one of several state or federal assistance programs (e.g., Medi-Cal or the National School Lunch Program) (Southern California Gas Company 2016). For seasonal heterogeneity, we split the calendar into winter months (October through March) and summer months (April through September). ${ }^{27}$

\footnotetext{
${ }^{26}$ Because we do not have identifying variation in income level (or season), the heterogeneities that we estimate should be taken as descriptive for the given group, rather than causal effects of income level or season. In other words, while we estimate heterogeneous elasticities with respect to income level, this heterogeneity may have nothing to do with income and could instead result from some other (omitted) variable that correlates with income/CARE status, e.g., the age and size of the physical home. However, identification of the sources of heterogeneity is not the goal of this paper; we aim to identify the elasticity of demand and demonstrate dimensions of heterogeneity. We leave it for future papers to identify the sources of these heterogeneities.

${ }^{27}$ This definition reflects southern California's two seasons: warm and slightly less warm.
} 


\subsubsection{Income heterogeneity}

To examine income-based heterogeneity in the price elasticity of demand for natural gas, we estimate the two-stage least squares equations 2 and 3 separately for CARE households and non-CARE households. Columns (3) and (4) of Table 8 supply the second-stage results from these regressions, providing estimates of the elasticity of demand by income level (CARE status).

The results in columns (3) and (4) of Table 8 suggest that the elasticity results in the previous section may in fact pool across heterogenous elasticities; we estimate that the price elasticity for CARE (lower-income) households is approximately twice that of non-CARE (higher-income) households. Specifically, using the marginal price, we estimate an elasticity of approximately $-0.24(0.080)$ for CARE (lower income) households and $-0.14(0.068)$ for non-CARE households. The "pooled" estimate corresponding to these results is $-0.21(0.071)$ (column (1) of Panel B in Table 6)—slightly higher than the midpoint between the CARE estimate and the non-CARE estimate.

\subsubsection{Seasonal heterogeneity}

To estimate seasonal heterogeneity in the price elasticity of demand for residential natural gas, we estimate the two-stage least squares equations 2 and 3 separately for winter months and for summer months. Columns (1) and (2) of Table 8 supply the second-stage results from these regressions, providing estimates of the elasticity of demand by season.

The results in columns (1) and (2) of Table 8 indicate a stark and significant difference between price elasticities in summer and winter months. Using marginal price, we estimate that the price elasticity of demand for natural gas in summer months is approximately 0.052 (0.029), which marginally differs from zero at the 10 percent level. The estimated elasticity for winter months is approximately $-0.38(0.14)$ and differs significantly from zero at the 1 percent level. The comparable "pooled" elasticity estimate corresponding to these results is approximately $-0.21(0.071)$ (column (1) of Panel B in Table 6). These results provide strong evidence that households' consumptive and price-response behaviors vary considerably by 
season-the winter-based elasticity is nearly twice the "pooled" elasticity. ${ }^{2829}$

\subsubsection{Income-by-season heterogeneity}

Having shown potential heterogeneity across income groups (CARE status) and season, we now examine the evidence that income groups' heterogeneity varies by season by interacting the two heterogeneity dimensions discussion above (income and season).

To estimate seasonal-by-income heterogeneity in the own-price elasticity of demand for residential natural gas, we estimate the two-stage least squares equations 2 and 3 separately for the four potentially heterogeneous subgroups: CARE households in the summer, nonCARE households in the summer, CARE households in the winter, and non-CARE households in the winter. Table 9 displays the second-stage results from these regressions, providing estimates of the elasticity of demand by season and CARE status.

The results in Table 9 are consistent with heterogeneous elasticities that depend upon the interaction between household income (CARE status) and season. In other words, the difference between a household's winter and summer price elasticities varies by the household's income level. Specifically, the results in Table 9 indicate that both income groups are essentially inelastic to prices in summer months; we estimate a "summertime" price elasticity of 0.046 (0.035) for CARE households and 0.074 (0.032) for non-CARE households. Both elasticities are positive, but only one is significantly different from zero and small. In winter months, both sets of consumers are significantly and substantially more responsive to price, but CARE households are particularly price responsive. We estimate the "wintertime" price elasticity of demand for natural gas is $-0.523(0.142)$ for CARE households and -0.317 (0.150) for non-CARE households. Again, the pooled elasticity corresponding to these results is approximately $-0.21(0.071)$ (column (1) in Table 6), which is a bit lower than the average of these four elasticities. Overall, Table 9 demonstrates the potential for substantial and important heterogeneity underlying commonly estimated pooled elasticities.

\footnotetext{
${ }^{28}$ Table A8 reproduces these heterogeneity results using average price-rather than marginal price-with very similar results.

${ }^{29}$ Because the current/relevant natural gas institutions divide the year into winter and summer-and because gas is primarily used for heating-we believe this summer/winter split is the most policy-relevant temporal disaggregation of the price elasticity of residential natural gas. We do not further disaggregate in time.
} 


\section{Conclusion and Discussion}

This paper combines millions of household natural gas bills with a multi-part identification strategy to provide the first micro-data based causal estimates of the own-price elasticity of demand for residential natural gas. Utilizing cross-border price variation between California's two largest natural gas utilities - resulting from the utilities differential pass-through of spot-market price variation-we isolate plausibly exogenous variation in residential natural gas prices. We estimate an elasticity of $-0.21[-0.35,-0.07]$. This estimate is robust to specification choices that include within-bill weather, several price instruments, and the definition/type of price. The point estimates for the own-price elasticity range from -0.23 to -0.17 across five measures of price. Given the robustness of these findings, this paper provides tight bounds on a policy-relevant parameter key to applications ranging from estimating the welfare benefits of fracking (Hausman and Kellogg 2015) to analyzing the regressivity of two-part tariffs (Borenstein and Davis 2012). Because households respond significantly to price changes two to four months prior to the period of consumption-and following Ito 2014 - we interpret these estimated elasticities as fairly medium-run elasticities. ${ }^{30}$

As a second important finding, we estimate that the own-price elasticity of demand varies significantly across seasons and customer types. We show that households on a popular low-income program, which subsidizes households' natural gas and electricity, appear to be twice as elastic in their response to price as households who are not part of the program. We also show that the price elasticity varies greatly across seasons. If we average across types of households, the summer price elasticity is close to, and only marginally different from, zero. The winter price elasticity is -0.38 . This heterogeneity suggests that households are much more price sensitive during their high-consumption months-the winter. These high-consumption winter months also correspond to the time of year in which consumers use natural gas in its most salient form: heating. When we break down the price elasticity across users and seasons, we show that subsidized consumers display the largest price sensitivity during the winter $(-0.52)$. Neither type of customer displays a substantial price response in the summer. These results suggest that, if suppliers want to pass through costs to (or

\footnotetext{
${ }^{30}$ Ito also notes that the medium-run elasticity is often the most policy-relevant elasticity.
} 
tax) consumers, summertime may be best-both for efficiency and for progressivity. This point hinges critically on the assumption that external costs from natural gas combustion are properly priced. For global pollutants, this is the case in California because the natural gas sector is part of California's cap and trade system.

Figure 8 illustrates the seasonal heterogeneity point with simple linear demand that is quite inelastic in the summer and moderately elastic in the winter-consistent with our results. The top row of Figure 8 demonstrates that, in this scenario, deadweight loss is substantially larger in the winter than in the summer. The bottom row simply doubles the summer tax and halves the winter tax, resulting in a minuscule increase in deadweight loss for the summer and a substantial reduction in deadweight loss in the winter-implying a considerable overall reduction in deadweight loss. ${ }^{31}$ Again, it is worth noting that this example also assumes (1) a first-best world (no unpriced costs to consumption) and (2) the goal of the policymaker is reducing deadweight loss conditional on some level of tax/cost recovery. If, for instance, natural-gas consumption includes an unpriced social cost, then increasing summer taxes and reducing winter taxes could potentially further reduce market efficiency by exacerbating the unpriced costs. Similarly, if the policymaker wishes to use the tax to reduce consumption, then our results suggest that imposing a per-unit tax in the winter is much more efficient than the same tax in the summer. ${ }^{32}$ However, our season-by-income results imply that the poor would bear the largest deadweight loss for such a tax.

The discussion above suggests a dimension for tax and cost-recovery efficiency-season of year-that we have not seen recommended in the literature or applied in practice. This fairly simple idea raises a wider question for future work: Along which other dimensions of consumer heterogeneity might we optimize current tax and cost-recovery policies? If policy is to take seasonal heterogeneity-or any other heterogeneity—into account, future work should decompose traditionally pooled elasticities and policy responses. Such work will provide policymakers with important parameters to improve market efficiency and enhance policy progressivity.

\footnotetext{
${ }^{31}$ This toy example is meant to illustrate an idea. The most efficient seasonal tax adjustment—conditional on a level of tax recovery-would likely not imply exactly doubling taxes in the summer and halving taxes in the winter.

${ }^{32}$ In terms of units of abatement per dollar of tax levied.
} 


\section{References}

Alberini, Anna, Will Gans, and Daniel Velez-Lopez. 2011. "Residential consumption of gas and electricity in the U.S.: The role of prices and income". Energy Economics 33 (5): 870-881. http://dx.doi.org/10.1016/j.eneco.2011.01.015.

Allcott, Hunt, and Dmitry Taubinsky. 2015. "Evaluating behaviorally motivated policy: Experimental evidence from the lightbulb market". American Economic Review 105 (8): 25012538.

Angrist, Joshua D., and Jörn-Steffen Pischke. 2009. Mostly harmless econometrics: an empiricist's companion. Princeton University Press.

Bao, Xuewei, and David W. Eaton. 2016. "Fault activation by hydraulic fracturing in western Canada". Science 354 (6318): 1406-1409.

Boiteux, M. 1971. "On the management of public monopolies subject to budgetary constraints". Journal of Economic Theory 3 (3): 219-240.

Borenstein, Severin, and Lucas W. Davis. 2012. "The Equity and Efficiency of Two-Part Tariffs in U.S. Natural Gas Markets". Journal of Law and Economics 55.

Brown, SPA, and MK Yücel. 1993. "The Pricing of Natural Gas in U.S. Markets". Economic Review-Federal Reserve Bank of Dallas, no. April: 41-52. http://www.dallasfed.org/assets/ documents/research/er/1993/er9302c.pdf.

California Energy Commission. 2015. "California Building Climate Zone Areas". Accessed March 01, 2017. http://www.energy.ca.gov/maps/renewable/building_climate_zones. html.

— . 2017. “Title 24: Building Energy Efficiency Program”. Accessed March 01, 2017. http://www.energy.ca.gov/title24/.

Chen, Yuyu, et al. 2013. "Evidence on the Impact of Sustained Exposure to Air Pollution on Life Expectancy from China 's Huai River Policy". Proceedings of the National Academy of Sciences of the United States of America 110 (32): 12936-12941. http://www.pnas.org/ content/early/2013/07/03/1300018110.short.

Chetty, Raj, Adam Looney, and Kory Kroft. 2009. "Salience and taxation: Theory and evidence". American Economic Review 99 (4): 1145-1177. arXiv: arXiv:1011.1669v3.

Davis, Lucas W., and Erich Muehlegger. 2010. "Do Americans consume too little natural gas? An empirical test of marginal cost pricing". RAND Journal of Economics.

Dell, Melissa. 2010. “The Persistent Effects of Peru's Mining Mita”. Econometrica 78 (6): 1863-1903. http://doi.wiley.com/10.3982/ECTA8121.

Environmental Protection Agency. 2013. "Natural Gas Extraction - Hydraulic Fracturing". Accessed August 05, 2016. https://www.epa.gov/hydraulicfracturing. 
Esri. 2017. "USA ZIP Code Areas". https://www. arcgis .com/home/item.html ? id = 8d2012a2016e484dafaac0451f9aea24.

Glanz, James. 2009. "Quake Fears Stall Energy Extraction Project". The New York Times July 13. http://www.nytimes.com/2009/07/14/business/energy-environment/14drill.html.

Hausman, Catherine, and Ryan Kellogg. 2015. "Welfare and Distributional Implications of Shale Gas". Brookings Papers on Economic Activity, no. Spring: 71-125.

Ito, Koichiro. 2014. "Do Consumers Respond to Marginal or Average Price? Evidence from Nonlinear Electricity Pricing". American Economic Review 104 (2): 537-563. http://pubs. aeaweb.org/doi/abs/10.1257/aer.104.2.537.

Levine, Steven, Paul Carpenter, and Anul Thapa. 2014. Understanding natural gas markets. Tech. rep. American Petroleum Institute. http://www.api.org/oil-and-natural-gas/energyprimers/natural-gas-markets.

Meier, Helena, and Katrin Rehdanz. 2010. "Determinants of residential space heating expenditures in Great Britain”. Energy Economics 32 (5): 949-959. http://dx.doi.org/10.1016/ j.eneco.2009.11.008.

National Academy of Sciences. 2016. "What You Need to Know About Energy: Natural Gas". Accessed August 05, 2016. http://needtoknow.nas.edu/energy/energy-sources/fossilfuels/natural-gas/.

Pacific Gas and Electric Company. 2016. "Guide to California Climate Zones". Accessed August 13, 2016. http://www.pge.com/myhome/edusafety/workshopstraining/pec/ toolbox/arch/climate/index.shtml.

PRISM Climate Group. 2004. "PRISM Gridded Climate Data". Oregon State University. http://prism.oregonstate.edu.

Ramsey, F. P. 1927. "A Contribution to the Theory of Taxation”. The Economic Journal 37 (145): 47-61.

Rehdanz, Katrin. 2007. "Determinants of residential space heating expenditures in Germany". Energy Economics 29 (2): 167-182. http://www.sciencedirect.com/science/article/pii/ S0140988306000405.

Sallee, James M. 2013. "Rational Inattention and Energy Efficiency". Journal of Law and Economics 57 (3): 781-820.

Solon, Garry, Steven J. Haider, and Jeffrey Wooldridge. 2015. "What are we weighting for?" Journal of Human Resources 50 (2): 301-316.

Southern California Gas Company. 2016. "California Alternate Rates for Energy (CARE)". Accessed August 08, 2016. https://www. socalgas .com/save-money-and-energy / assistance-programs/california-alternate-rates-for-energy. 
U.S. Energy Information Administration. 2016a. "Average annual natural gas spot price in 2015 was at lowest level since 1999". Accessed November 04, 2017. https://www.eia. gov/todayinenergy/detail.php?id=24412\#.

— . 2016b. "Electric Power Monthly - Net Generation by Energy Source: Total (All Sectors), 2006-May 2016”. Accessed August 05, 2016. https://www.eia.gov/electricity/monthly/ epm_table_grapher.cfm?t=epmt_1_1.

— . 2016c. "Frequently Asked Questions". Accessed March 01, 2017. https://www.eia.gov/ tools $/$ faqs $/$ faq. $\mathrm{cfm}$ ? id $=45 \& \mathrm{t}=8$.

— . 2016d. "Henry Hub Natural Gas Spot Price". Accessed August 10, 2016. https://www. eia.gov/dnav/ng/hist/rngwhhdD.htm.

— . 2017. "Maps: Layer Information for Interactive State Maps - Natural Gas Interstate and Intrastate Pipelines". Accessed October 23, 2017. https://www.eia.gov/maps/layer_infom.php.

Woolridge, Jeffrey. 2009. Introductory Econometrics - A Modern Approach. 4e. Mason, OH: South-Western Cengage Learning. 


\section{Figures}

Figure 1: U.S. natural gas institutional organization

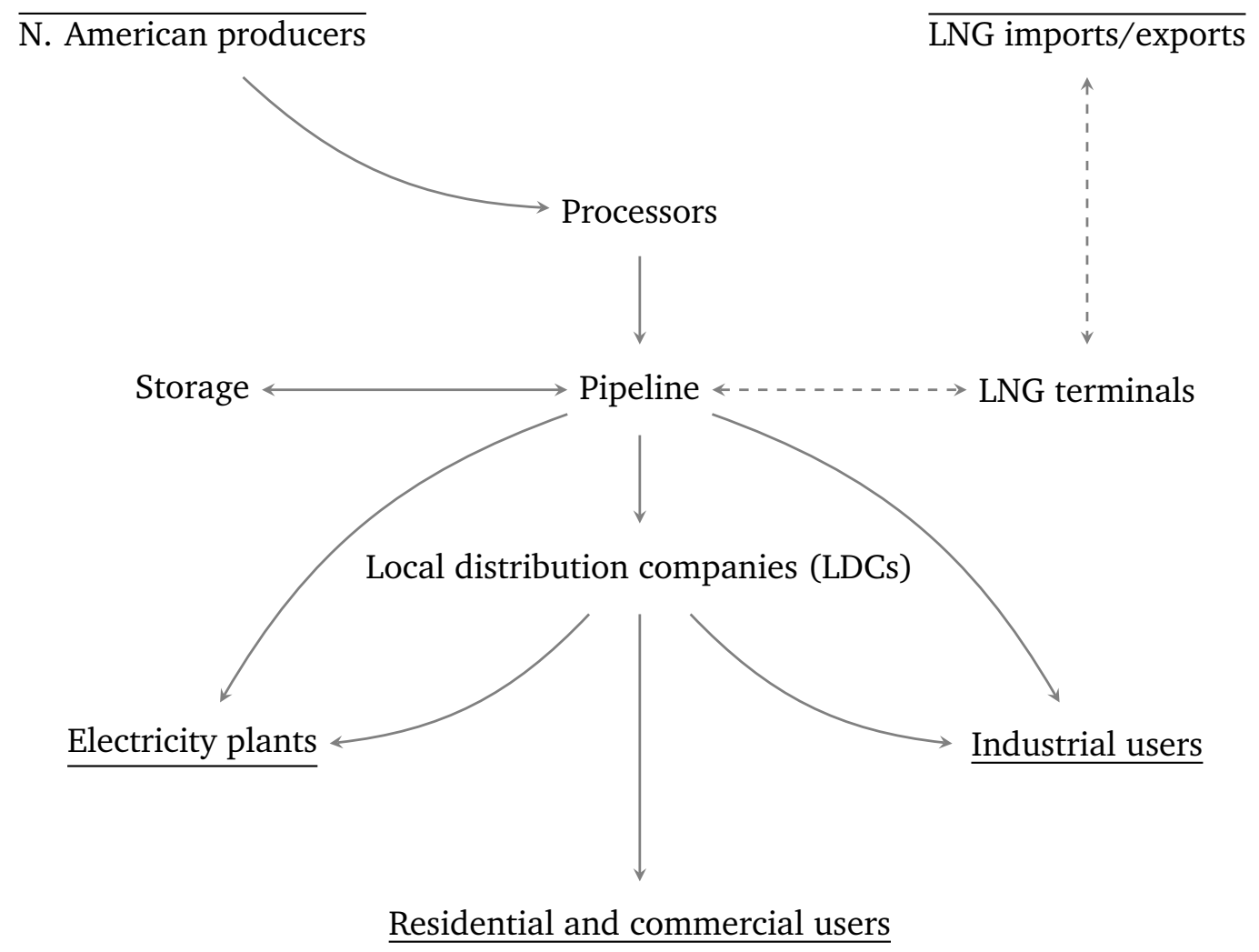

Notes: Overbars represent points of entry into the U.S. natural gas market; underbars represent end points in the market; all other labels represent intermediaries. Arrow directions correspond to the direction of the flow of natural gas. The acronym $L N G$ abbreviates liquid natural gas. This figure is based on Levine, Carpenter, and Thapa with modification following Brown and Yücel. 
Figure 2: U.S. natural gas pipeline network

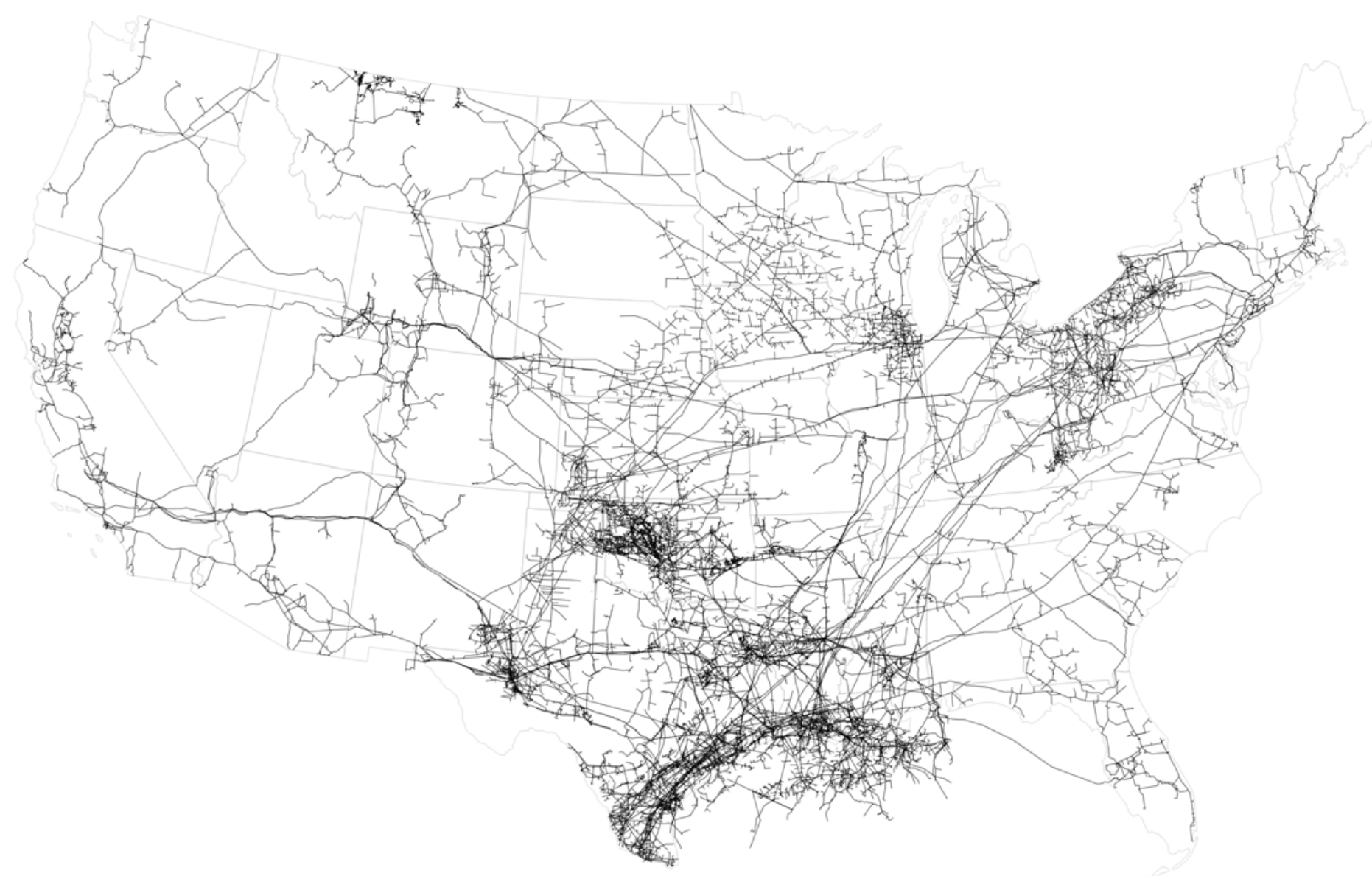

Notes: This map depicts the intra- and inter-state natural gas pipeline network for the (continental) United States (in black) overlayed on a map of the (continental) U.S. (light gray). Source: U.S. Energy Information Administration 
Figure 3: Henry Hub natural gas spot price: Daily, 1997-2016

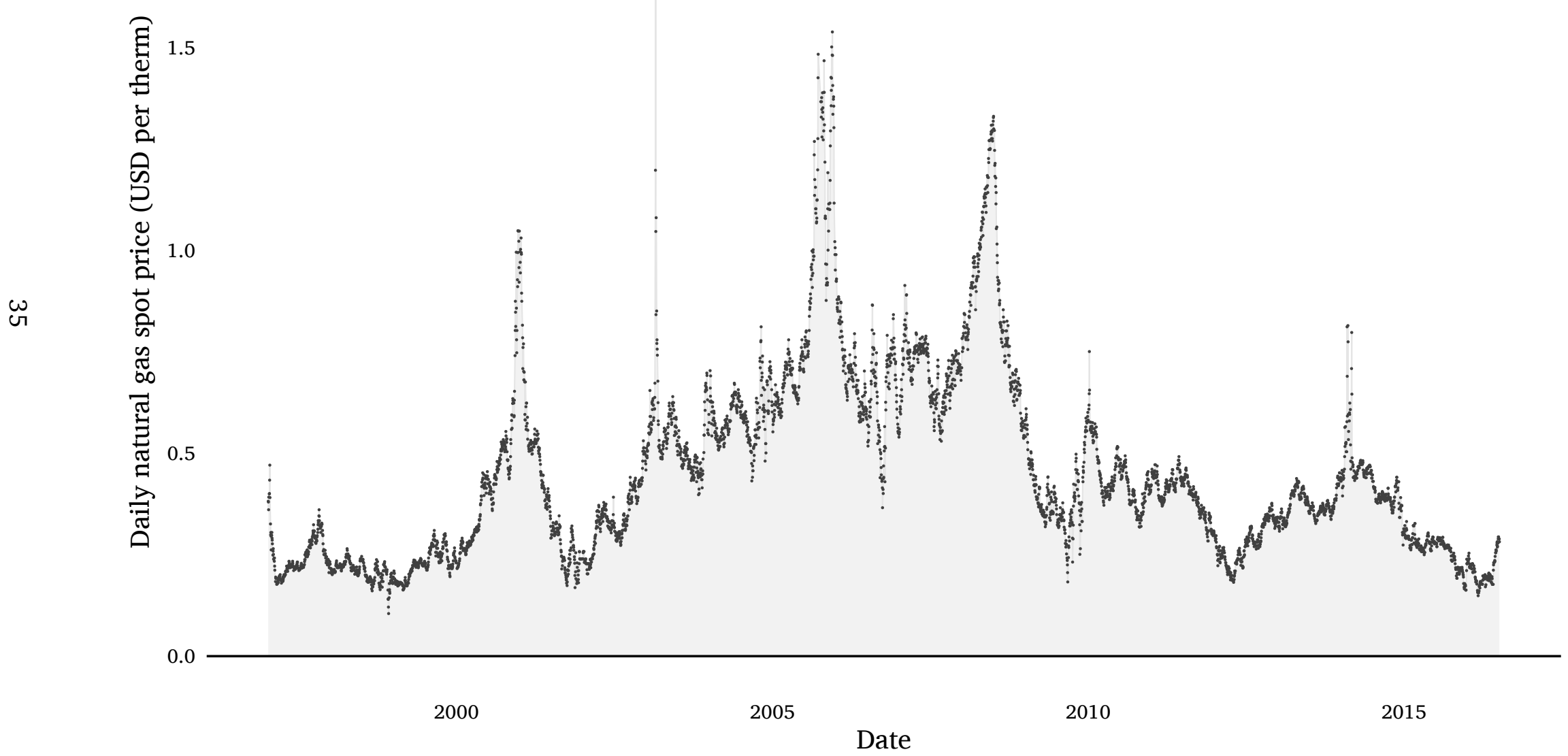

Source: U.S. Energy Information Administration 
Figure 4: Households' allowances and prices

(a) Allowance and marginal vs. average price example: PG\&E, January 2009, climate zone R

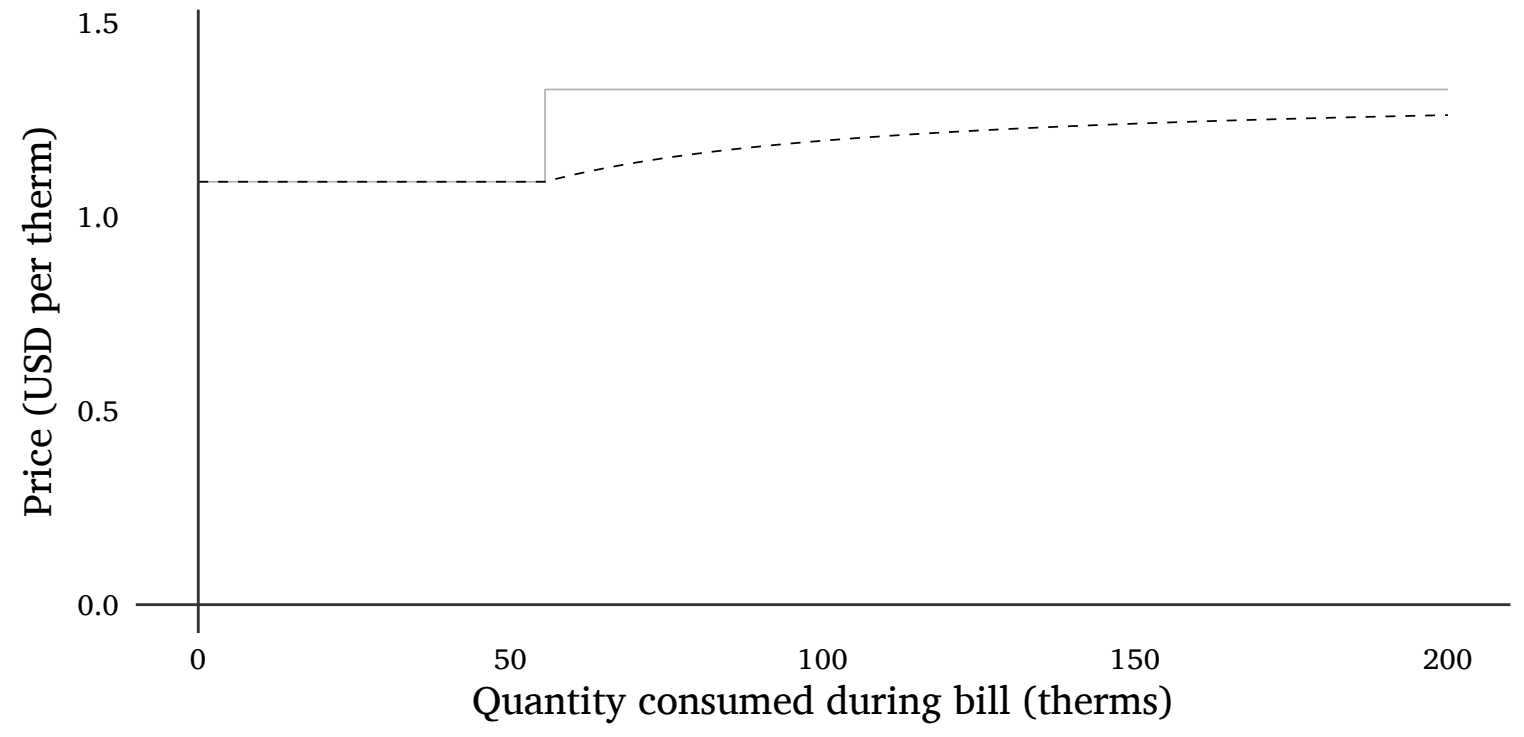

Marginal price - - - - Average price

(b) Tier-one daily allowances over time: PG\&E (zone R) and SoCalGas (zone 1), 2009-2015

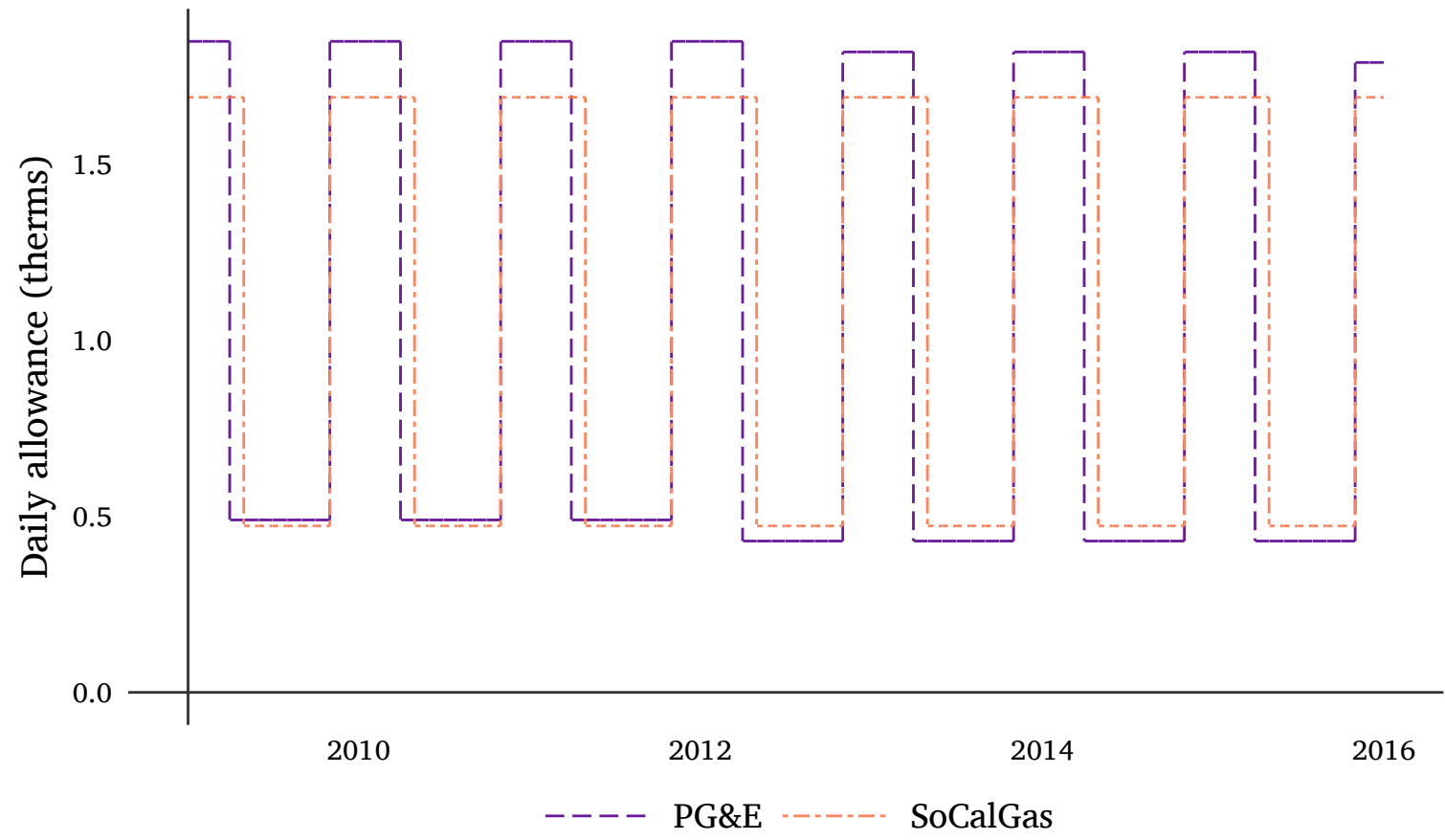

Notes: Households receive daily allowances for baseline (first-tier) consumption as a function of location and season (e.g., climate zone $R$, January 2009). The household pays the second-tier price on all units that exceed its allowance-comparing total consumption (during the billing period) to total allowance (daily allowance summed across the bills' days). 
Figure 5: Natural gas service areas and the study-area discontinuity

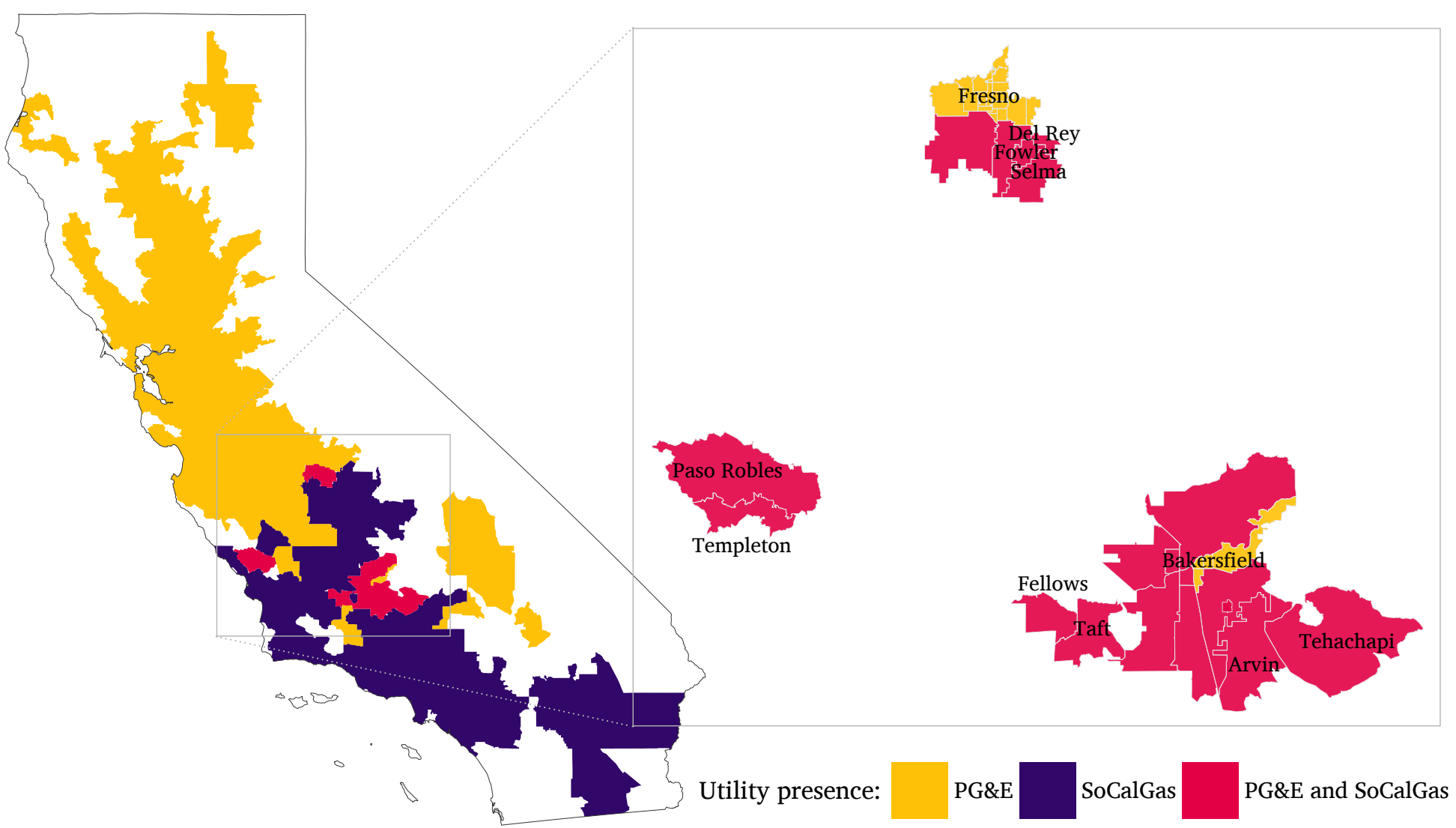

Notes: The left side of the figure displays PG\&E's and SoCalGas's services areas (by 5-digit zip code). The right side of the figure zooms in on three clusters of cities that receive service from both utilities. These three clusters of cities encompass 39 zip codes; 18 of these (5-digit) zip codes receive service from both PG\&E and SoCalGas. These 18 zip codes represent the main study area for the paper. 
Figure 6: Prices across utilities, tiers, and in the spot market, 2009-2015

(a) Price regimes over time: PG\&E and SoCalGas, 2009-2015

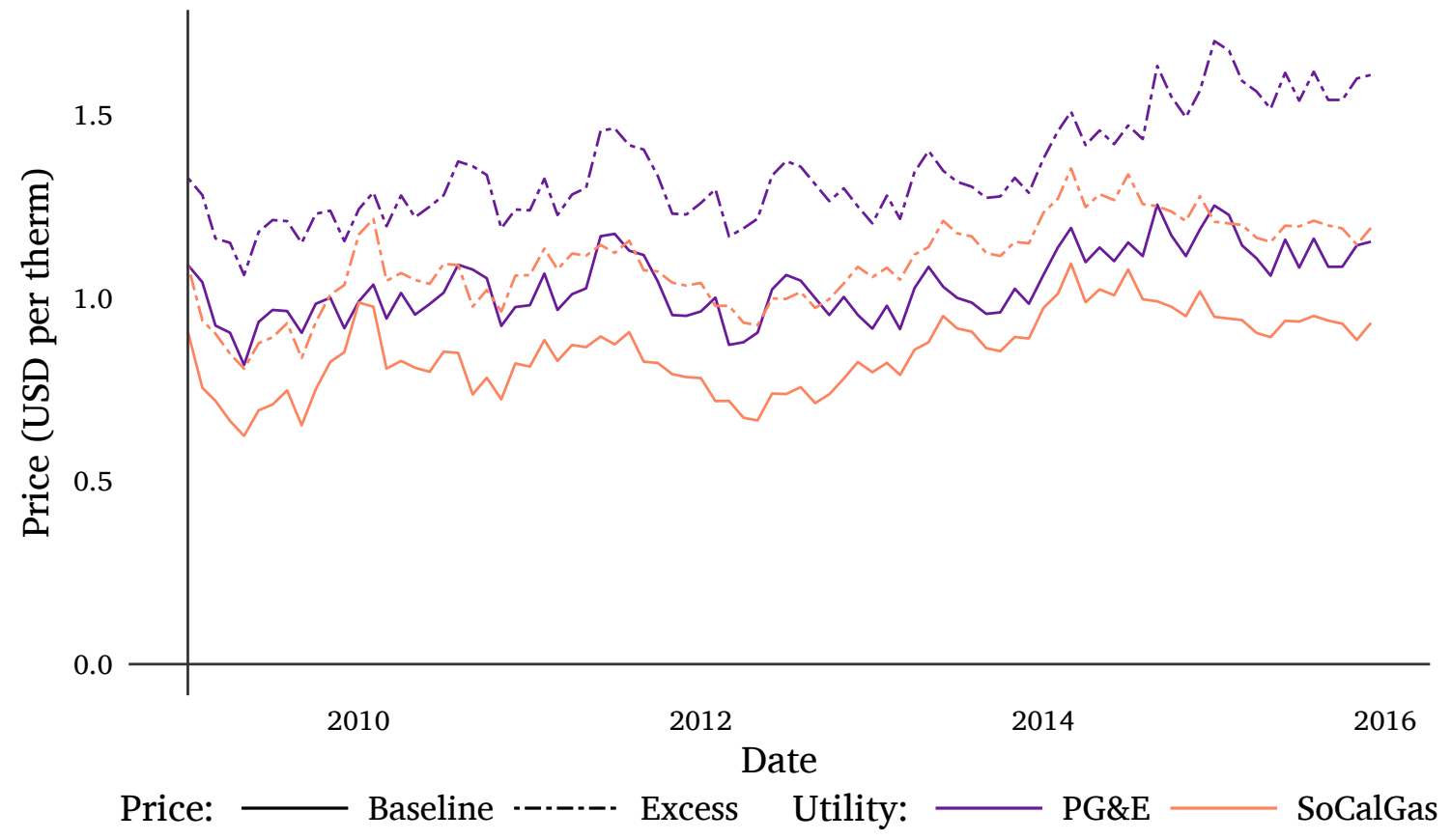

(b) Correlation across prices Three relevant natural gas price series, 2009-2015

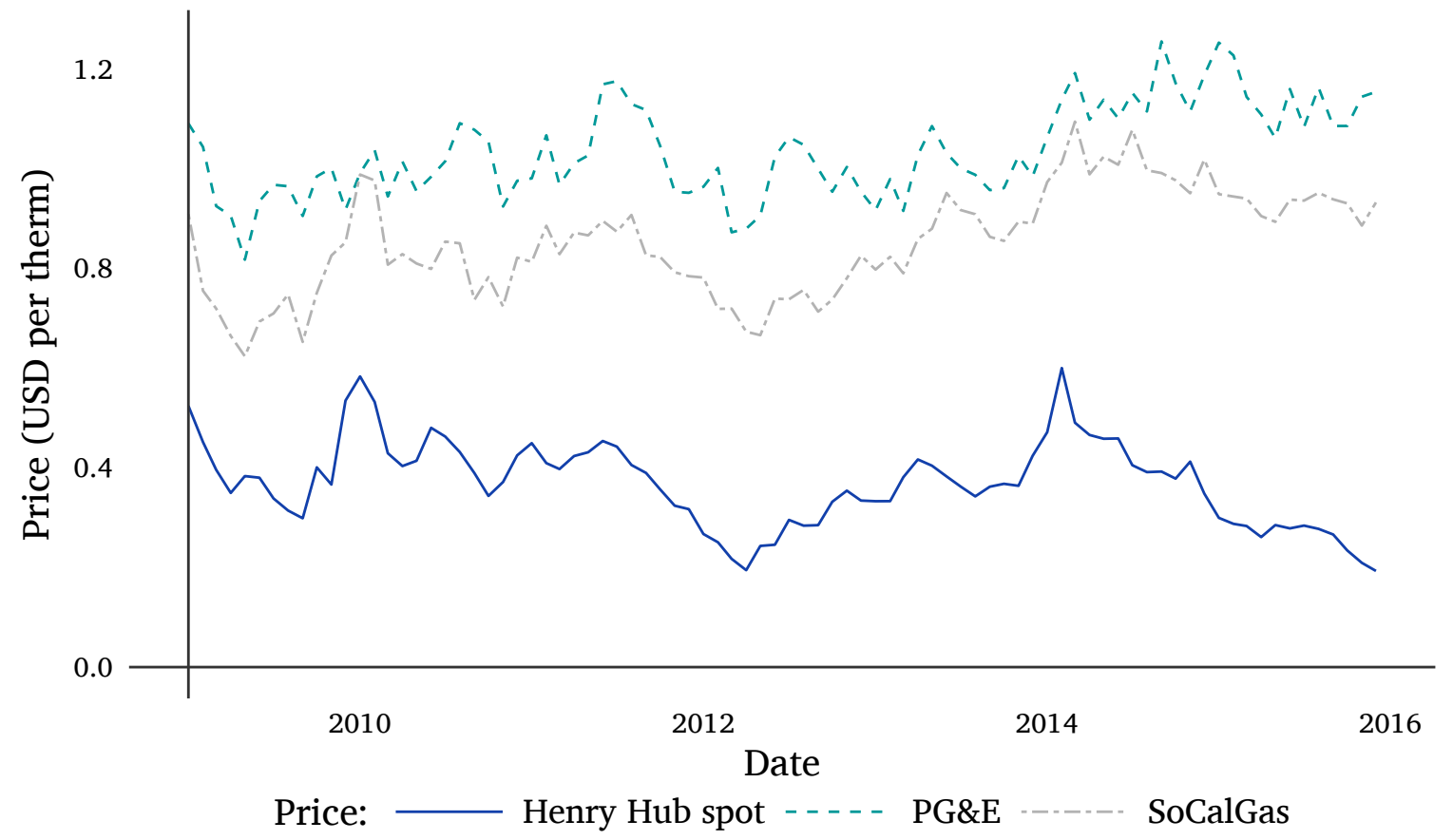

Notes: Baseline refers to first-tier price, i.e., the price a household pays for its first therm of natural gas. Excess refers to the second-tier price, i.e., the price a household pays for each therm that exceeds its first-tier allowance (see Figure 4). The Henry Hub spot price is generally recognized as a national benchmark (U.S. Energy Information Administration 2016a; Levine, Carpenter, and Thapa 2014). 
Figure 7: Calendar months and billing periods: Four 30-day bills and five months

\begin{tabular}{ccccccc}
$\mathrm{S}$ & $\mathrm{M}$ & $\mathrm{T}$ & $\mathrm{W}$ & $\mathrm{T}$ & $\mathrm{F}$ & $\mathrm{S}$ \\
\hline 1 & 2 & 3 & 4 & 5 & 6 & 7 \\
8 & 9 & 10 & 11 & 12 & 13 & 14 \\
\hline 15 & 16 & 17 & 18 & 19 & 20 & 21 \\
\hline 22 & 23 & 24 & 25 & 26 & 27 & 28 \\
\hline 29 & 30 & 31 & & & &
\end{tabular}
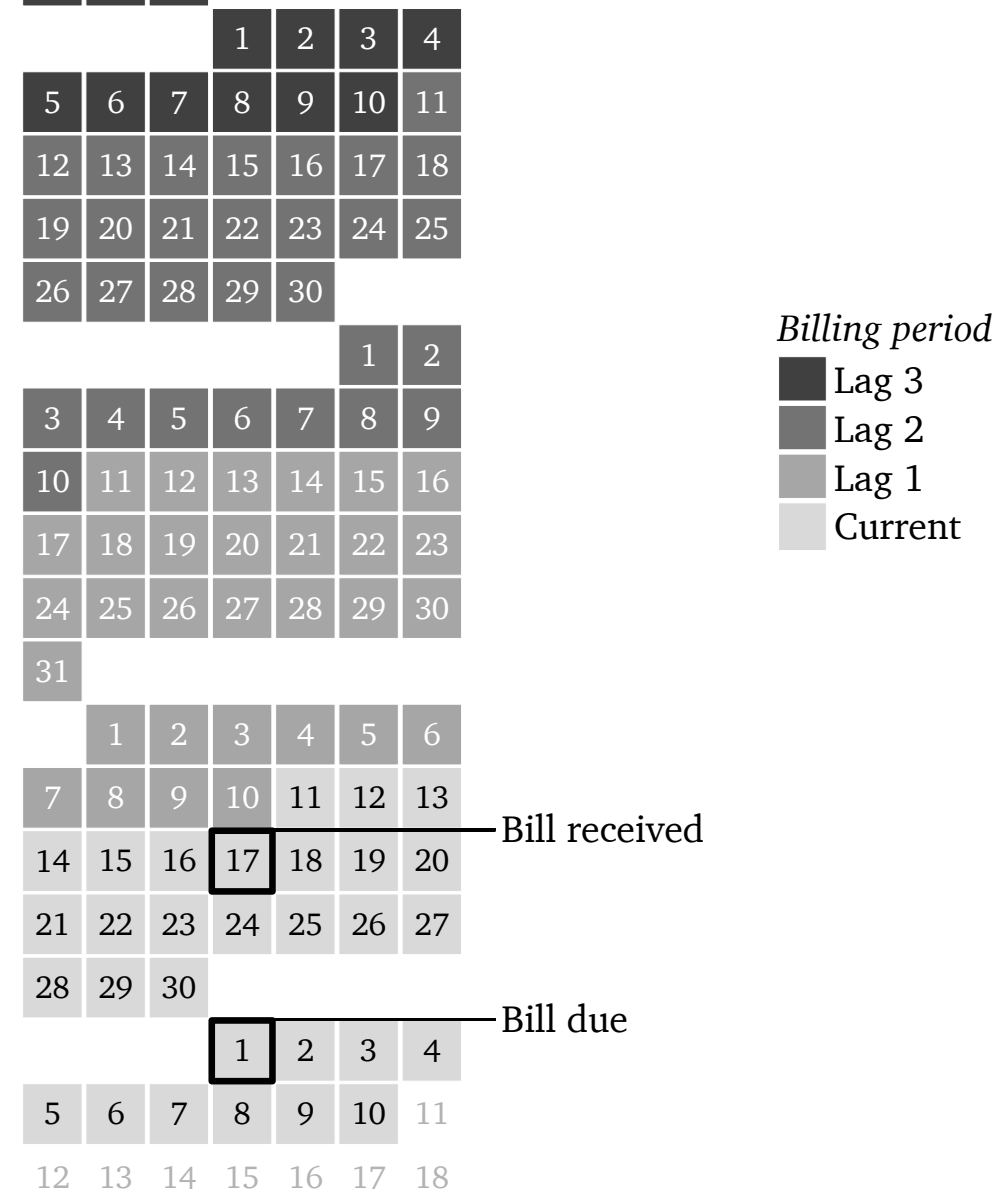

Notes: The household receives its bill from the Lag 1 period on the fifth business day of its current billing period (the $17^{\text {th }}$ ). Payment for the Lag 1 bill is due two weeks later (on the $1^{\text {st }}$ ). Now consider the question "Which lag of price is relevant?" Current: For the household to know the price structure for its current billing period, it must pay attention to the approval status of its utility's advice-letters correspondence with the CPUC. Lag 1: Again, unless the household pays attention to the utility's CPUC-approved advice letters, it will not know the prices in the Lag 1 billing period until it receives and opens the bill. The bill arrives several days into the new period, and if the household does not see the bill until payment, it may not learn about the prices of the Lag 1 bill until the current billing period is nearly complete. Autopay may extend this moment of salience even further into the future. Lag 2: Throughout the entirety of the Current billing period, the household will know the prices from its Lag 2 bill, and for a non-zero amount of time, the Lag 2 bill is likely to be the most recent set of prices the household knows. Lag 3: Same level of knowledge as Lag 2 but less recent. 
Figure 8: Increasing tax efficiency using seasonal heterogeneity

(a) Current tax: Summer

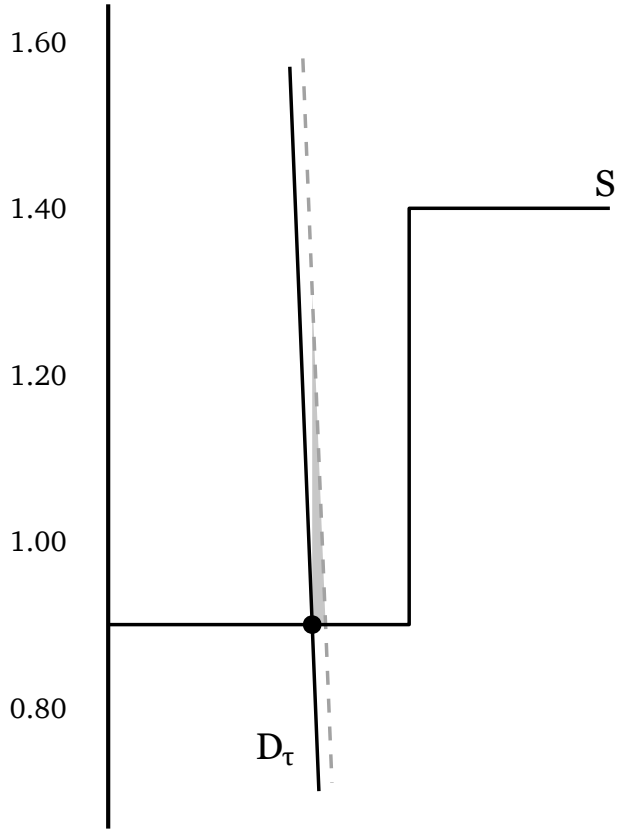

(c) Proposed tax: Summer

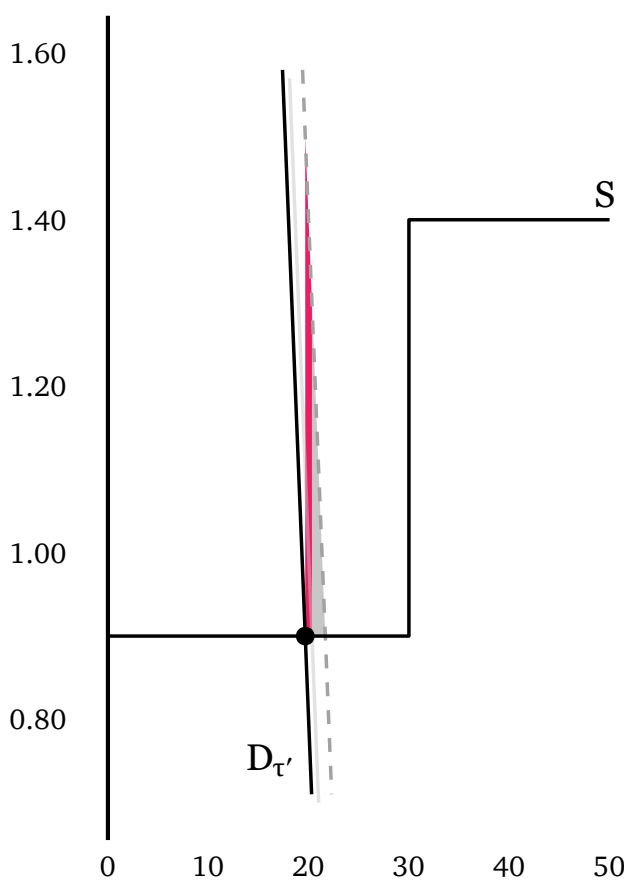

(b) Current tax: Winter

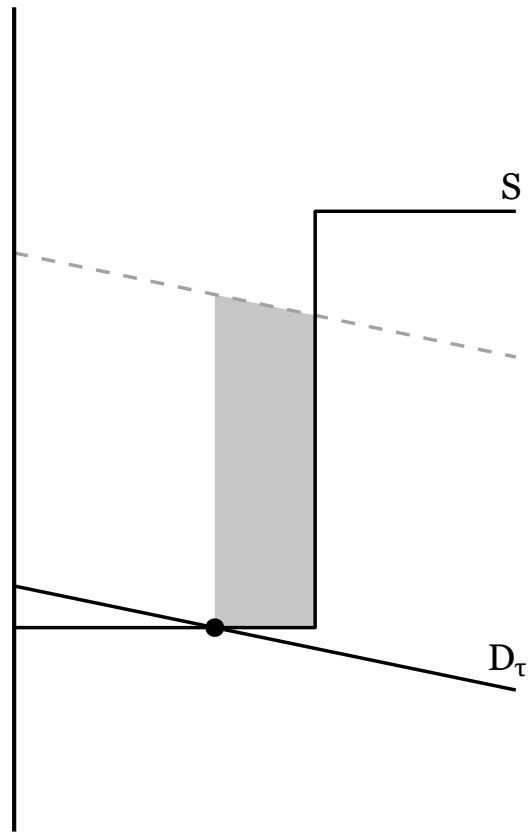

(d) Proposed tax: Winter

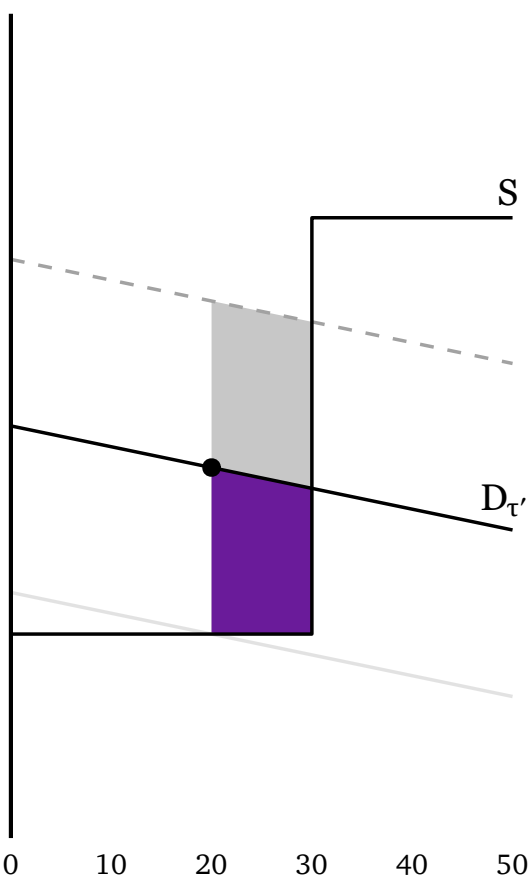

Notes: Each figure presents the combination of a tax (current $v s$. proposed) and a season; the $x$ and $y$ axes are quantity and price, respectively. The top row illustrates the two seasons under the current tax, where households pay the same tax per therm in both seasons. The shaded gray area gives the deadweight loss (DWL) under this tax. Proposed tax: The bottom row doubles the tax in the summer-increasing DWL by the narrow pink region-and halves the tax in the winter-reducing DWL by the purple region. Overall DWL decreases. 


\section{Tables}

Table 1: Prior point estimates: The price elasticity of demand for residential natural gas

\begin{tabular}{lrr}
\hline \hline Paper & Data & Estimate \\
\hline Davis and Muehlegger (2010) & US state panel & -0.278 \\
Maddala et al. (1997) & US state panel & -0.09 to -0.18 \\
Garcia-Cerrutti (2000) & Calif. county panel & -0.11 \\
Hausman and Kellogg (2015) & US state panel & -0.11 \\
Herbert and Kreil (1989) & Monthly time series & -0.36 \\
Houthakker and Taylor (1970) & Time series & -0.15 \\
Metcalf and Hassett (1999) & RECS HH panel & -0.08 to -0.71 \\
Meier and Rehdanz (2010) & UK HH panel & -0.34 to -0.56 \\
Rehdanz (2007) & Germany HH panel & -0.44 to -0.63 \\
\hline
\end{tabular}

Sources: Authors and Alberini et al. (2011)

Table 2: Billing data summaries

\begin{tabular}{lrrrrr}
\hline \hline & \multicolumn{2}{c}{ Full dataset } & & \multirow{2}{*}{ Border-area dataset } \\
\cline { 2 - 3 } & PG\&E & SoCalGas & & PG\&E & SoCalGas \\
\hline N. 5-digit zip codes & 597 & 611 & 18 & 18 \\
N. 9-digit zip codes & 680,846 & 610,207 & 18,047 & 16,295 \\
N. unique households & $5,888,276$ & $2,526,503$ & & 152,418 & 68,407 \\
N. bills & $180,663,705$ & $95,335,393$ & & $3,401,947$ & $2,352,141$ \\
Approx. value (USD) & $\$ 5.71 \mathrm{~B}$ & $\$ 3.28 \mathrm{~B}$ & & $\$ 120 \mathrm{M}$ & $\$ 70.5 \mathrm{M}$ \\
\hline
\end{tabular}

Notes: Full dataset refers to all of the PG\&E and SoCalGas bills in the data. Border-area (discontinuity) dataset refers to the subset of the full dataset for households located in the 18 5-digit zip codes served by both utilities during 2010-2014. 
Table 3: Numerical summaries: Prices, quantities, and other variables of interest

\begin{tabular}{|c|c|c|c|c|c|c|c|c|}
\hline \multirow[b]{3}{*}{ Variable } & \multicolumn{3}{|c|}{$5 \%$ Sample of California } & \multicolumn{5}{|c|}{ Border-discontinuity sample } \\
\hline & \multirow[b]{2}{*}{ Overall } & \multicolumn{2}{|c|}{ Split by utility } & \multirow[b]{2}{*}{ Overall } & \multicolumn{2}{|c|}{ Split by season } & \multicolumn{2}{|c|}{ Split by CARE } \\
\hline & & PG\&E & SoCalGas & & Winter & Summer & CARE & Non-Care \\
\hline Baseline price & $\begin{array}{c}0.8901 \\
{[0.1686]}\end{array}$ & $\begin{array}{c}0.9823 \\
{[0.1206]}\end{array}$ & $\begin{array}{c}0.7432 \\
{[0.1242]}\end{array}$ & $\begin{array}{c}0.9026 \\
{[0.1419]}\end{array}$ & $\begin{array}{c}0.8836 \\
{[0.1361]}\end{array}$ & $\begin{array}{c}0.9204 \\
{[0.1448]}\end{array}$ & $\begin{array}{c}0.8080 \\
{[0.0854]}\end{array}$ & $\begin{array}{c}0.9811 \\
{[0.1311]}\end{array}$ \\
\hline Average price & $\begin{array}{c}1.0138 \\
{[0.1845]}\end{array}$ & $\begin{array}{c}1.1053 \\
{[0.1439]}\end{array}$ & $\begin{array}{c}0.8680 \\
{[0.1439]}\end{array}$ & $\begin{array}{c}1.0211 \\
{[0.1621]}\end{array}$ & $\begin{array}{c}1.0008 \\
{[0.1583]}\end{array}$ & $\begin{array}{c}1.0402 \\
{[0.1633]}\end{array}$ & $\begin{array}{c}0.9086 \\
{[0.1004]}\end{array}$ & $\begin{array}{c}1.1147 \\
{[0.1430]}\end{array}$ \\
\hline Marginal price & $\begin{array}{c}1.0206 \\
{[0.2260]}\end{array}$ & $\begin{array}{c}1.1277 \\
{[0.186]}\end{array}$ & $\begin{array}{c}0.8500 \\
{[0.173]}\end{array}$ & $\begin{array}{c}1.0387 \\
{[0.1983]}\end{array}$ & $\begin{array}{c}1.0121 \\
{[0.1905]}\end{array}$ & $\begin{array}{c}1.0637 \\
{[0.2021]}\end{array}$ & $\begin{array}{c}0.9338 \\
{[0.1448]}\end{array}$ & $\begin{array}{c}1.1259 \\
{[0.1944]}\end{array}$ \\
\hline Therms & $\begin{array}{c}35.4626 \\
{[33.7995]}\end{array}$ & $\begin{array}{c}37.7541 \\
{[36.0107]}\end{array}$ & $\begin{array}{c}31.8135 \\
{[29.5791]}\end{array}$ & $\begin{array}{c}33.8273 \\
{[30.7697]}\end{array}$ & $\begin{array}{c}50.9544 \\
{[35.2487]}\end{array}$ & $\begin{array}{c}17.7311 \\
{[11.5803]}\end{array}$ & $\begin{array}{c}33.1136 \\
{[28.7629]}\end{array}$ & $\begin{array}{c}34.4204 \\
{[32.3306]}\end{array}$ \\
\hline Days & $\begin{array}{c}30.3992 \\
{[1.4275]}\end{array}$ & $\begin{array}{c}30.4282 \\
{[1.2667]}\end{array}$ & $\begin{array}{c}30.3530 \\
{[1.6505]}\end{array}$ & $\begin{array}{c}30.3994 \\
{[1.3038]}\end{array}$ & $\begin{array}{c}30.5876 \\
{[1.3843]}\end{array}$ & $\begin{array}{c}30.2225 \\
{[1.1966]}\end{array}$ & $\begin{array}{c}30.4040 \\
{[1.2761]}\end{array}$ & $\begin{array}{c}30.3955 \\
{[1.3263]}\end{array}$ \\
\hline Therms per day & $\begin{array}{c}1.1592 \\
{[1.0921]}\end{array}$ & $\begin{array}{c}1.2355 \\
{[1.1698]}\end{array}$ & $\begin{array}{c}1.0378 \\
{[0.9426]}\end{array}$ & $\begin{array}{c}1.1063 \\
{[0.9936]}\end{array}$ & $\begin{array}{c}1.6588 \\
{[1.1354]}\end{array}$ & $\begin{array}{c}0.5871 \\
{[0.3838]}\end{array}$ & $\begin{array}{c}1.0840 \\
{[0.9304]}\end{array}$ & $\begin{array}{c}1.1249 \\
{[1.0429]}\end{array}$ \\
\hline Total bill & $\begin{array}{c}36.8703 \\
{[39.5758]}\end{array}$ & $\begin{array}{c}42.3938 \\
{[44.0564]}\end{array}$ & $\begin{array}{c}28.0747 \\
{[29.0445]}\end{array}$ & $\begin{array}{c}34.9508 \\
{[33.8812]}\end{array}$ & $\begin{array}{c}52.0750 \\
{[39.8973]}\end{array}$ & $\begin{array}{c}18.8573 \\
{[14.0069]}\end{array}$ & $\begin{array}{c}30.3135 \\
{[27.2567]}\end{array}$ & $\begin{array}{c}38.8040 \\
{[38.1017]}\end{array}$ \\
\hline (Percent) CARE & $27.43 \%$ & $26.35 \%$ & $29.15 \%$ & $45.38 \%$ & $45.00 \%$ & $45.74 \%$ & $100 \%$ & $0 \%$ \\
\hline
\end{tabular}

Notes: Unbracketed values provide the variables' means; bracketed values denote the variables' standard deviations. The 5\% sample of California is based upon 5\% of PG\&E's and SoCalGas's natural gas bills from 2010-2014, sampling at the 5-digit zip code. The border-discontinuity sample represents all bills from PG\&E and SoCalGas for the 18 5-digit zip codes served by both utilities from 2010-2014. 
Table 4: Balance on observables: Comparing utilities' customers across the discontinuity

\begin{tabular}{|c|c|c|c|c|c|c|}
\hline \multirow[b]{2}{*}{ Variable } & \multicolumn{3}{|c|}{ Non-CARE } & \multicolumn{3}{|c|}{ CARE } \\
\hline & PG\&E & SoCalGas & Diff. & PG\&E & SoCalGas & Diff. \\
\hline \multicolumn{7}{|l|}{ Panel A: Summer } \\
\hline Therms consumed & $\begin{array}{l}17.61 \\
{[10.8]}\end{array}$ & $\begin{array}{l}17.29 \\
{[11.7]}\end{array}$ & $\begin{array}{c}0.32 \\
{[11.3]}\end{array}$ & $\begin{array}{l}19.35 \\
{[11.3]}\end{array}$ & $\begin{array}{l}18.00 \\
{[11.3]}\end{array}$ & $\begin{array}{c}1.34 \\
{[11.3]}\end{array}$ \\
\hline Days in bill & $\begin{array}{l}30.31 \\
{[1.16]}\end{array}$ & $\begin{array}{l}29.97 \\
{[1.36]}\end{array}$ & $\begin{array}{c}0.34 \\
{[1.28]}\end{array}$ & $\begin{array}{l}30.29 \\
{[1.16]}\end{array}$ & $\begin{array}{l}29.96 \\
{[1.36]}\end{array}$ & $\begin{array}{c}0.33 \\
{[1.22]}\end{array}$ \\
\hline Allowance & $\begin{array}{c}14.17 \\
{[0.805]}\end{array}$ & $\begin{array}{l}17.22 \\
{[8.05]}\end{array}$ & $\begin{array}{l}-3.05 \\
{[6.14]}\end{array}$ & $\begin{array}{c}14.14 \\
{[0.851]}\end{array}$ & $\begin{array}{l}17.11 \\
{[8.17]}\end{array}$ & $\begin{array}{l}-2.96 \\
{[4.33]}\end{array}$ \\
\hline Total bill & $\begin{array}{l}21.58 \\
{[14.8]}\end{array}$ & $\begin{array}{l}16.45 \\
{[12.4]}\end{array}$ & $\begin{array}{c}5.14 \\
{[13.8]}\end{array}$ & $\begin{array}{l}19.03 \\
{[12.4]}\end{array}$ & $\begin{array}{l}13.52 \\
{[9.35]}\end{array}$ & $\begin{array}{c}5.51 \\
{[11.9]}\end{array}$ \\
\hline $\begin{array}{l}\text { HDDs } \\
\quad \text { (thousands) }\end{array}$ & $\begin{array}{c}0.16 \\
{[0.309]}\end{array}$ & $\begin{array}{c}0.25 \\
{[0.407]}\end{array}$ & $\begin{array}{c}-0.08 \\
{[0.367]}\end{array}$ & $\begin{array}{c}0.14 \\
{[0.267]}\end{array}$ & $\begin{array}{c}0.26 \\
{[0.418]}\end{array}$ & $\begin{array}{c}-0.12 \\
{[0.315]}\end{array}$ \\
\hline$N$ & 810,949 & 961,824 & $1,772,773$ & 973,063 & 320,082 & $1,293,145$ \\
\hline \multicolumn{7}{|l|}{ Panel B: Winter } \\
\hline Therms consumed & $\begin{array}{l}51.40 \\
{[33.8]}\end{array}$ & $\begin{array}{l}54.07 \\
{[35.7]}\end{array}$ & $\begin{array}{l}-2.67 \\
{[34.8]}\end{array}$ & $\begin{array}{l}49.60 \\
{[31.1]}\end{array}$ & $\begin{array}{l}49.94 \\
{[33.1]}\end{array}$ & $\begin{array}{l}-0.34 \\
{[31.6]}\end{array}$ \\
\hline Days in bill & $\begin{array}{l}30.55 \\
{[1.31]}\end{array}$ & $\begin{array}{l}30.78 \\
{[1.8]}\end{array}$ & $\begin{array}{l}-0.24 \\
{[1.59]}\end{array}$ & $\begin{array}{l}30.57 \\
{[1.31]}\end{array}$ & $\begin{array}{l}30.83 \\
{[1.81]}\end{array}$ & $\begin{array}{l}-0.26 \\
{[1.45]}\end{array}$ \\
\hline Allowance & $\begin{array}{l}46.70 \\
{[12.8]}\end{array}$ & $\begin{array}{l}49.07 \\
{[10.7]}\end{array}$ & $\begin{array}{l}-2.37 \\
{[11.8]}\end{array}$ & $\begin{array}{l}47.16 \\
{[12.4]}\end{array}$ & $\begin{array}{l}49.68 \\
{[10.4]}\end{array}$ & $\begin{array}{c}-2.52 \\
{[12]}\end{array}$ \\
\hline Total bill & $\begin{array}{l}59.79 \\
{[41.8]}\end{array}$ & $\begin{array}{l}50.60 \\
{[36.4]}\end{array}$ & $\begin{array}{c}9.19 \\
{[39.4]}\end{array}$ & $\begin{array}{l}45.35 \\
{[30.3]}\end{array}$ & $\begin{array}{l}36.51 \\
{[26.5]}\end{array}$ & $\begin{array}{c}8.84 \\
{[29.7]}\end{array}$ \\
\hline $\begin{array}{l}\text { HDDs } \\
\quad \text { (thousands) }\end{array}$ & $\begin{array}{c}1.69 \\
{[0.467]}\end{array}$ & $\begin{array}{c}1.73 \\
{[0.437]}\end{array}$ & $\begin{array}{c}-0.04 \\
{[0.452]}\end{array}$ & $\begin{array}{c}1.70 \\
{[0.439]}\end{array}$ & $\begin{array}{c}1.75 \\
{[0.422]}\end{array}$ & $\begin{array}{c}-0.05 \\
{[0.435]}\end{array}$ \\
\hline$N$ & 746,140 & 800,037 & $1,546,177$ & 871,795 & 270,198 & $1,141,993$ \\
\hline
\end{tabular}

Notes: Unbracketed values provide the variables' means; bracketed values denote the variables' standard deviations. The standard deviations below the difference column (Diff.) are pooled across utilities. The difference column denotes the difference in means across utilities for the given cross-section of data. For example, the rightmost Diff. column in Panel A gives the difference between the PG\&E mean and the SoCalGas mean for CARE households in summer months, $\bar{X}_{\mathrm{PGE}}-\bar{X}_{\mathrm{SCG}}$. CARE households participate in the California Alternative Rates for Energy (CARE) program. CARE targets low-income households and provides a 20 percent discount on natural gas bills. Heating degree days (HDDs) are in thousands. We calculate the number of heating degrees for day $t$ with mean temperature $\bar{T}_{t}$ (in ${ }^{\circ} \mathrm{F}$ ) as $\operatorname{HDD}_{t}=\mathbb{1}\left\{\bar{T}_{t}<65\right\} \times\left(65-\bar{T}_{t}\right)$. The HDDs variable above is thus $\mathrm{HDDS}=\sum_{t} \mathrm{HDD}_{t} / 1000$. 
Table 5: OLS Results: Estimating elasticities, varying the dataset, price, and fixed effects

\begin{tabular}{|c|c|c|c|c|c|c|}
\hline & \multicolumn{6}{|c|}{ Dependent variable: Log(Consumption, daily avg.) } \\
\hline & (1) & (2) & (3) & (4) & (5) & (6) \\
\hline Log(Marginal price) & $\begin{array}{c}0.4698^{* * *} \\
(0.0106)\end{array}$ & $\begin{array}{c}0.4346^{* * *} \\
(0.0136)\end{array}$ & $\begin{array}{c}0.4276^{* * *} \\
(0.0134)\end{array}$ & & & \\
\hline Log(Baseline price) & & & & $\begin{array}{c}0.0217 \\
(0.0147)\end{array}$ & $\begin{array}{c}-0.0918^{* * *} \\
(0.0201)\end{array}$ & $\begin{array}{c}-0.1009^{* * *} \\
(0.0209)\end{array}$ \\
\hline Bill HDDs & $\mathrm{T}$ & $\mathrm{T}$ & $\mathrm{T}$ & $\mathrm{T}$ & $\mathrm{T}$ & $\mathrm{T}$ \\
\hline Household FE & $\mathrm{T}$ & $\mathrm{T}$ & $\mathrm{T}$ & $\mathrm{T}$ & $\mathrm{T}$ & $\mathrm{T}$ \\
\hline Month-of-sample FE & $\mathrm{T}$ & $\mathrm{T}$ & $\mathrm{F}$ & $\mathrm{T}$ & $\mathrm{T}$ & $\mathrm{F}$ \\
\hline City by month-of-sample FE & $\mathrm{F}$ & $\mathrm{F}$ & $\mathrm{T}$ & $\mathrm{F}$ & $\mathrm{F}$ & $\mathrm{T}$ \\
\hline Sample & $5 \%$ CA & Border & Border & $5 \% \mathrm{CA}$ & Border & Border \\
\hline$N$ & $12,855,910$ & $5,754,088$ & $5,754,088$ & $12,855,910$ & $5,754,088$ & $5,754,088$ \\
\hline
\end{tabular}

Notes: Each column denotes a separate regression. Errors are two-way clustered within (1) household and (2) utility by climate-zone by billing-cycle (the level at which price varies). All regressions include heating degree days (HDDs) within the households' billing cycle. Base or baseline price refers to the price the household pays for its first unit (therm) of natural gas. Each price in the table is the second lag of price, i.e., the prices from two bills prior to the current bill. Significance levels: $* 10 \%, * * 5 \%, * * * 1 \%$. 
Table 6: First- and second-stage results:

Instrumenting consumers' prices with the Henry Hub spot price

Dependent variable: $\log ($ Consumption, daily avg.)

Panel A: First-stage results

(1)

(2)

(3)

(4)

(5)

\begin{tabular}{lccccc} 
& Marginal & Average & Avg. Mrg. & Baseline & Sim. Mrg. \\
\hline Spot price & $\begin{array}{ccc}0.3679^{* * *} \\
(0.0774)\end{array}$ & $\begin{array}{c}0.3697^{* * *} \\
(0.0521)\end{array}$ & $\begin{array}{c}0.3384^{* * *} \\
(0.0570)\end{array}$ & $\begin{array}{c}0.4699^{* * *} \\
(0.0434)\end{array}$ & $\begin{array}{c}0.3949^{* * *} \\
(0.0840)\end{array}$ \\
$\begin{array}{cccc}\text { Spot price } \\
\quad \times \text { SoCalGas }\end{array}$ & $\begin{array}{c}0.7868^{* * *} \\
(0.0299)\end{array}$ & $\begin{array}{c}0.7174^{* * *} \\
(0.0186)\end{array}$ & $\begin{array}{c}0.9389^{* * *} \\
(0.0198)\end{array}$ & $\begin{array}{c}0.8212^{* * *} \\
(0.0176)\end{array}$ & $\begin{array}{c}0.8174^{* * *} \\
(0.0317)\end{array}$ \\
\hline
\end{tabular}

Panel B: Second-stage results

\begin{tabular}{lccccc}
$\begin{array}{l}\text { Log(Price) } \\
\text { (instrumented) }\end{array}$ & $\begin{array}{c}-0.2098^{* * *} \\
(0.0706)\end{array}$ & $\begin{array}{c}-0.2312^{* * *} \\
(0.076)\end{array}$ & $\begin{array}{c}-0.1734^{* * *} \\
(0.0585)\end{array}$ & $\begin{array}{c}-0.2030^{* * *} \\
(0.065)\end{array}$ & $\begin{array}{c}-0.1705^{* *} \\
(0.0698)\end{array}$ \\
\hline First-stage F stat. & 418.4 & 899.4 & $1,311.0$ & $1,333.2$ & 369.9 \\
Bill HDDs & $\mathrm{T}$ & $\mathrm{T}$ & $\mathrm{T}$ & $\mathrm{T}$ & $\mathrm{T}$ \\
Household FE & $\mathrm{T}$ & $\mathrm{T}$ & $\mathrm{T}$ & $\mathrm{T}$ & $\mathrm{T}$ \\
City mo.-of-sample FE & $\mathrm{T}$ & $\mathrm{T}$ & $\mathrm{T}$ & $\mathrm{T}$ & $\mathrm{T}$ \\
$N$ & $5,754,085$ & $5,754,085$ & $5,754,085$ & $5,754,085$ & $4,682,526$
\end{tabular}

Notes: Each column denotes a separate regression. Errors are two-way clustered within (1) household and (2) utility by climate-zone by billing-cycle (the level at which price varies). All regressions include heating degree days (HDDs) within the houesholds' bill. (HH) Spot price refers to the weekly average spot price for natural gas at Louisiana's Henry Hub in the week preceding the utility's price change. Each price in the table is the second lag of price, i.e., the prices from two bills prior to the current bill. Avg. or average price is the total bill divided by quantity. Avg. Mrg. or average marginal price denotes the quantity-weighted average of the household's marginal price. Sim. Mrg. or simulated marginal price is the household's marginal price (using the relevant pricing regime) as a function of the household's historical consumption patterns (lagged bills 10 through 14). As discussed in the empirical strategy section, the numbers of observations differ due to the lags required to calculate the simulated instrument for marginal price. Significance levels: *10\%, **5\%, ***1\%. 
Table 7: Comparing lags, second-stage results: Marginal and average prices with HH spot price IV

Dependent variable: $\log ($ Consumption, daily avg.)

\begin{tabular}{|c|c|c|c|c|c|c|c|c|}
\hline & \multicolumn{4}{|c|}{ Marginal Price } & \multicolumn{4}{|c|}{ Average Price } \\
\hline & $(1)$ & (2) & (3) & (4) & (5) & $(6)$ & $(7)$ & (8) \\
\hline & 1 Lead & No lag & $1 \mathrm{Lag}$ & 2 Lags & 1 Lead & No lag & $1 \mathrm{Lag}$ & 2 Lags \\
\hline Log(Price) & 0.0480 & -0.1121 & -0.0223 & $-0.2098^{* * *}$ & 0.0515 & -0.1244 & -0.0177 & $-0.2312^{* * *}$ \\
\hline instrumented & $(0.0902)$ & $(0.0762)$ & $(0.0668)$ & $(0.0706)$ & $(0.0972)$ & $(0.0805)$ & $(0.0730)$ & $(0.0760)$ \\
\hline First-stage F stat. & 326.7 & 337.9 & 410.8 & 418.4 & 679.1 & 725.8 & 884.4 & 899.4 \\
\hline Bill HDDs & $\mathrm{T}$ & $\mathrm{T}$ & $\mathrm{T}$ & $\mathrm{T}$ & $\mathrm{T}$ & $\mathrm{T}$ & $\mathrm{T}$ & $\mathrm{T}$ \\
\hline Household FE & $\mathrm{T}$ & $\mathrm{T}$ & $\mathrm{T}$ & $\mathrm{T}$ & $\mathrm{T}$ & $\mathrm{T}$ & $\mathrm{T}$ & $\mathrm{T}$ \\
\hline City month-of-sample FE & $\mathrm{T}$ & $\mathrm{T}$ & $\mathrm{T}$ & $\mathrm{T}$ & $\mathrm{T}$ & $\mathrm{T}$ & $\mathrm{T}$ & $\mathrm{T}$ \\
\hline$N$ & $5,501,467$ & $5,754,088$ & $5,754,088$ & $5,754,085$ & $5,501,467$ & $5,754,088$ & $5,754,088$ & $5,754,085$ \\
\hline
\end{tabular}

a $\quad$ Notes: With regard to lags: No lag refers to the price for the household's contemporaneous bill; 1 Lag refers to the price on the household's previous bill; etc. Avg. or average price is the total bill divided by quantity. (HH) Spot price refers to the weekly average spot price for natural gas at Louisiana's Henry Hub in the week preceding the utility's price change. Each column denotes a separate regression. Errors are two-way clustered within (1) household and (2) utility by climate-zone by billing-cycle (the level at which price varies). All regressions include heating degree days (HDDs) within the households' billing period. Significance levels: * $10 \%$, **5\%, ***1\%. 
Table 8: Heterogeneity by season or income:

Second-stage results, instrumenting marginal price with $\mathrm{HH}$ spot price

Dependent variable: $\log ($ Consumption, daily avg.)

\begin{tabular}{|c|c|c|c|c|}
\hline & \multicolumn{4}{|c|}{ Marginal Price } \\
\hline & \multicolumn{2}{|c|}{ Split by Season } & \multicolumn{2}{|c|}{ Split by CARE (Income) } \\
\hline & $\begin{array}{c}(1) \\
\text { Summer }\end{array}$ & $\begin{array}{c}(2) \\
\text { Winter }\end{array}$ & $\begin{array}{c}(3) \\
\text { CARE }\end{array}$ & $\begin{array}{c}\text { (4) } \\
\text { Non-CARE }\end{array}$ \\
\hline $\begin{array}{l}\text { Log(Price) } \\
\quad \text { instrumented }\end{array}$ & $\begin{array}{c}0.0519^{*} \\
(0.0285)\end{array}$ & $\begin{array}{c}-0.3769^{* * *} \\
(0.1399)\end{array}$ & $\begin{array}{c}-0.2443^{* * *} \\
(0.0794)\end{array}$ & $\begin{array}{c}-0.1413^{* *} \\
(0.0684)\end{array}$ \\
\hline First-stage F stat. & 319.6 & 174.2 & 393.7 & 335.8 \\
\hline Bill HDDs & $\mathrm{T}$ & $\mathrm{T}$ & $\mathrm{T}$ & $\mathrm{T}$ \\
\hline Household FE & $\mathrm{T}$ & $\mathrm{T}$ & $\mathrm{T}$ & $\mathrm{T}$ \\
\hline City month-of-sample FE & $\mathrm{T}$ & $\mathrm{T}$ & $\mathrm{T}$ & $\mathrm{T}$ \\
\hline$N$ & $3,065,917$ & $2,688,168$ & $2,435,135$ & $3,318,950$ \\
\hline
\end{tabular}

Notes: Each column denotes a separate regression. Errors are two-way clustered within (1) household and (2) utility by climate-zone by billing-cycle (the level at which price varies). All regressions include heating degree days (HDDs) within the households' billing period. Each price in the table is the second lag of price, i.e., the prices from two bills prior to the current bill. Summer includes April through September. Winter includes October through March. CARE households participate in the California Alternative Rates for Energy (CARE) program. CARE targets low-income households and provides a 20 percent discount on natural gas bills. We estimate the heterogeneity results by splitting the sample along the dimension(s) of heterogeneity and then individually estimating the models. Significance levels: *10\%, **5\%,***1\%. 
Table 9: Heterogeneity by season and income:

Second-stage results, instrumenting marginal price with $\mathrm{HH}$ spot price

Dependent variable: $\log ($ Consumption, daily avg.)

\begin{tabular}{lcccc}
\hline \hline & \multicolumn{4}{c}{ Marginal Price } \\
\cline { 2 - 5 } & $(1)$ & $(2)$ & $(3)$ & $(4)$ \\
& Summer & Summer & Winter & Winter \\
& CARE & Non-CARE & CARE & Non-CARE \\
\hline Log(Price) & 0.0457 & $0.0742^{* *}$ & $-0.5226^{* * *}$ & $-0.3173^{* *}$ \\
instrumented & $(0.0353)$ & $(0.0324)$ & $(0.1424)$ & $(0.1498)$ \\
\hline First-stage F stat. & 303.4 & 237.1 & 145.6 & 156.7 \\
Bill HDDs & $\mathrm{T}$ & $\mathrm{T}$ & $\mathrm{T}$ & $\mathrm{T}$ \\
Household FE & $\mathrm{T}$ & $\mathrm{T}$ & $\mathrm{T}$ & $\mathrm{T}$ \\
City month-of-sample FE & $\mathrm{T}$ & $\mathrm{T}$ & $\mathrm{T}$ & $\mathrm{T}$ \\
$N$ & $1,293,144$ & $1,772,773$ & $1,141,991$ & $1,546,177$ \\
\hline
\end{tabular}

Notes: Each column denotes a separate regression. Errors are two-way clustered within (1) household and (2) utility by climate-zone by billing-cycle (the level at which price varies). All regressions include heating degree days (HDDs) within the households' billing period. Each price in the table is the second lag of price, i.e., the prices from two bills prior to the current bill. Summer includes April through September. Winter includes October through March. CARE households participate in the California Alternative Rates for Energy (CARE) program. CARE targets low-income households and provides a 20 percent discount on natural gas bills. We estimate the heterogeneity results by splitting the sample along the dimension(s) of heterogeneity and then individually estimating the models. Significance levels: $* 10 \%, * * 5 \%, * * * 1 \%$. 


\section{Table of contents}

1 Introduction $\quad 1$

2 Institutional setting $\quad 4$

2.1 Market segments . . . . . . . . . . . . . . . . 5

2.2 Natural gas pricing in California . . . . . . . . . . . . . . 6

3 Data $\quad 8$

3.1 Natural gas billing data . . . . . . . . . . . . . . . . 8

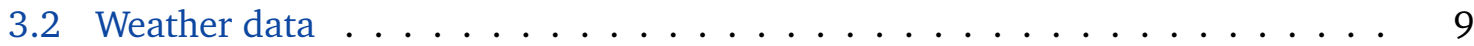

4 Empirical strategy $\quad 10$

4.1 Estimating equation . . . . . . . . . . . . . . . 10

4.2 Challenges to identification . . . . . . . . . . . . . . 11

4.3 Solutions for identification . . . . . . . . . . . . . . . . . 14

4.3 .1 Discontinuities ............................ 14

4.3 .2 Instrumental variables . . . . . . . . . . . . . . . 16

4.3.3 Instrumented prices and simulated instruments . . . . . . . . . . . 19

5 Results $\quad 22$

5.1 Pooled price elasticity of demand for natural gas . . . . . . . . . . . . . 23

5.2 Heterogeneity . . . . . . . . . . . . . . . . . 25

5.2 .1 Income heterogeneity $\ldots \ldots \ldots \ldots \ldots$

5.2 .2 Seasonal heterogeneity . . . . . . . . . . . . . . 26

5.2 .3 Income-by-season heterogeneity $\ldots \ldots \ldots 27$

6 Conclusion and Discussion $\quad 28$

$\begin{array}{lll}7 & \text { Figures } & 33\end{array}$

8 Tables $\quad 41$

Descriptive tables . . . . . . . . . . . . . . . . . . 41

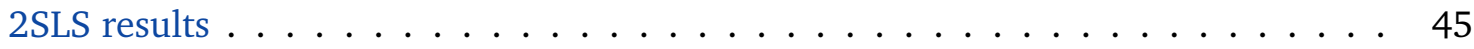

Heterogeneity results . . . . . . . . . . . . . . . . . . 47

$\begin{array}{ll}\text { Table of contents } & 49\end{array}$

A Appendix $\mathbf{5 2}$

A.1 Appendix figures . . . . . . . . . . . . . . . . 52

A.2 Appendix tables . . . . . . . . . . . . . . . . 56

A.3 Calculating bills . . . . . . . . . . . . . . . . 67

A.4 Data work . . . . . . . . . . . . . . . . 67 


\section{List of Figures}

1 U.S. natural gas institutional organization . . . . . . . . . . . . . 33

2 U.S. natural gas pipeline network . . . . . . . . . . . . . . . 34

3 Henry Hub natural gas spot price: Daily, 1997-2016 . . . . . . . . . . 35

4 Households' allowances and prices . . . . . . . . . . . . . . . 36

5 Natural gas service areas and the study-area discontinuity . . . . . . . . . 37

6 Prices across utilities, tiers, and in the spot market, 2009-2015 . . . . . . 38

7 Calendar months and billing periods: Four 30-day bills and five months . . 39

8 Increasing tax efficiency using seasonal heterogeneity . . . . . . . . . . . . . 40

A1 California's 16 CEC climate zones determine daily allowance within season 52

A2 Example bill: PG\&E residential natural gas bill . . . . . . . . . . . . 53

A3 PRISM: Mean temperature raster for 15 June 2010 . . . . . . . . . . . . . . 54

A4 Expanding the study area: Zip codes neighboring the study's zip codes . . . 55

\section{List of Tables}

1 Prior point estimates: The price elasticity of demand for residential natural gas 41

2 Billing data summaries . . . . . . . . . . . . . . . . . . . . 41

3 Numerical summaries: Prices, quantities, and other variables of interest . . . 42

4 Balance on observables: Comparing utilities' customers across the discontinuity 43

5 OLS Results: Estimating elasticities, varying the dataset, price, and fixed effects 44

6 First- and second-stage results: Instrumenting consumers' prices with the Henry Hub spot price . . . . . . . . 45

7 Comparing lags, second-stage results: Marginal and average prices with $\mathrm{HH}$ spot price IV . . . . . . . . . . . . . . . . . . . . . . . 46

8 Heterogeneity by season or income:

Second-stage results, instrumenting marginal price with $\mathrm{HH}$ spot price . . . . 47

9 Heterogeneity by season and income:

Second-stage results, instrumenting marginal price with HH spot price . . . . 48

A1 Price correlation: Bivariate correlations between types of prices . . . . . . 56

A2 Testing the simulated instrument:

Regressing marginal price on simulated marginal price . . . . . . . . . . 56

A3 Comparing lags, second-stage results: Marginal price with $\mathrm{HH}$ spot price IV 57

A4 Comparing lags, second-stage results: Sim. marginal price with $\mathrm{HH}$ spot price IV . . . . . . . . . . . . . . . . 57

A5 Comparing lags, second-stage results: Avg. marginal price with $\mathrm{HH}$ spot price IV . . . . . . . . . . . . . . . . . . . . . . . 58

A6 Comparing lags, second-stage results: Avgerage price with $\mathrm{HH}$ spot price IV 58 
A7 Comparing lags, second-stage results: Baseline price with $\mathrm{HH}$ spot price IV 59

A8 Heterogeneity by season or income:

Second-stage results, instrumenting average price with $\mathrm{HH}$ spot price . . . . . 60

A9 Heterogeneity by season and income:

Second-stage results, instrumenting average price with $\mathrm{HH}$ spot price . . . . . 61

A10 First-stage results:

Robustness to specification: Marginal price instrumented with spot price . . . 62

A11 Second-stage results:

Robustness to specification: Marginal price instrumented with spot price . . . 62

A12 Second-stage results:

Robustness to specification: Average price instrumented with spot price . . . . 63

A13 Second-stage results:

Robustness to specification: Avg. mrg. price instrumented with spot price . . . 63

A14 Second-stage results:

Robustness to specification: Baseline price instrumented with spot price . . . 64

A15 Second-stage results:

Robustness to specification: Baseline price instrumented with spot price . . . 64

A16 Second-stage results: Extending the set of zip codes to neighboring zip codes 65

A17 Billing data description: Columns within the billing data . . . . . . . . . 66 


\section{A Appendix}

\section{A.1 Appendix figures}

Figure A1: California's 16 CEC climate zones determine daily allowance within season

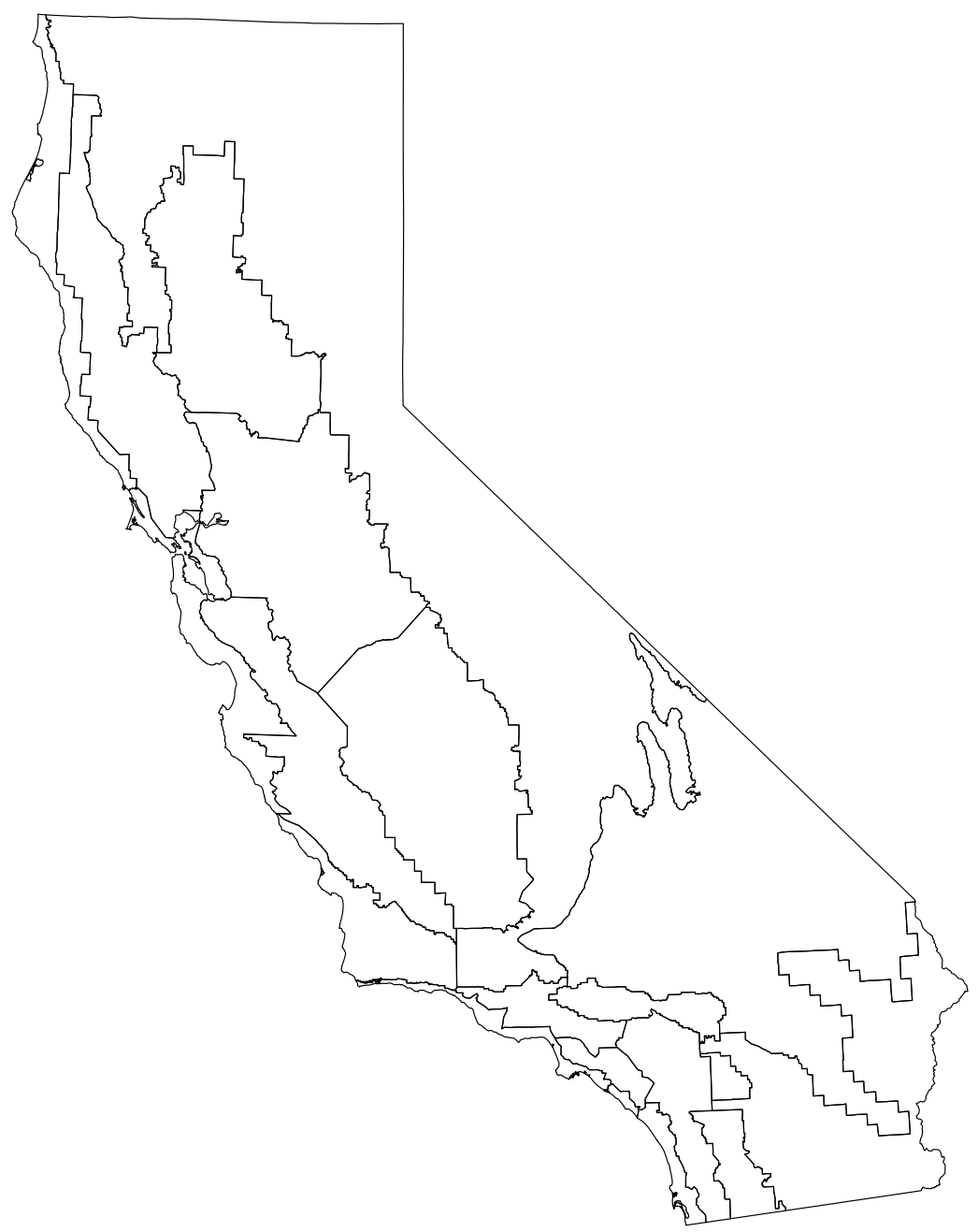

Notes: The shapefile underlying this map comes from the California Energy Commission (CEC). This map constitutes the CEC's climate-based building zones, which affect a number of energy policies, including households' baseline allowances. California Energy Commission 2015, 2017 
Figure A2: Example bill: PG\&E residential natural gas bill

\section{ENERGY STATEMENT}

www.pge.com/MyEnergy

Account No: Statement Date:

Due Date:

\section{$01 / 17 / 2017$}

\section{Details of Gas Charges}

11/24/2016 - 12/23/2016 (30 billing days)

Service For

Service Agreement ID:

Rate Schedule: G1 T Residential Service

\begin{tabular}{ll|l|} 
& \multicolumn{1}{r}{$\boldsymbol{V}$} \\
\hline $11 / 24 / 2016-11 / 30 / 2016$ & Your Tier Usage 1 & 2 \\
\hline
\end{tabular}

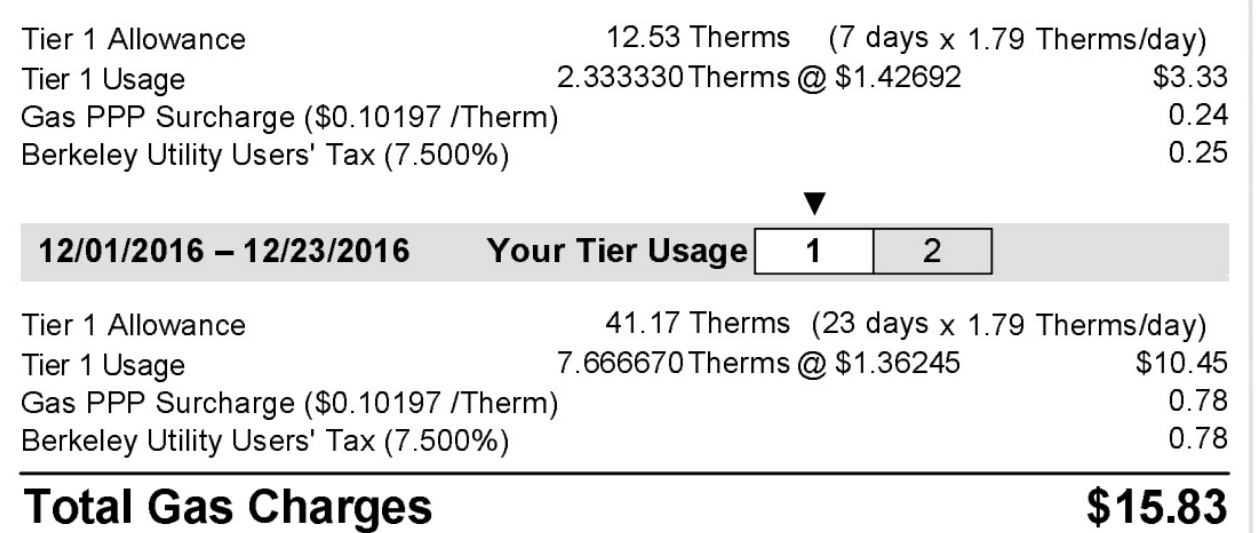

Notes: This 30-day bill for a PG\&E customer (one of the authors) overlaps two calendar months in $2016: 7$ days in November (24-30) and 23 days in December (01-23). Because PG\&E's prices vary with the calendar month, PG\&E needs to split consumption by calendar month. To achieve this task, PG\&E assumes the customer consumed evenly across all days in the bill. Specifically, PG\&E calculates that the customer consumed 10 therms and assigns the same amount of consumption to each day during the 30 -day period. Thus, PG\&E assigns $10 \times 7 / 30 \approx 2.33$ to November (the consumer spent 7 days in November in this 30 -day bill) and $10 \times 23 / 30 \approx 7.67$ to December (the consumer spent 23 days in November in this 30-day bill). 
Figure A3: PRISM: Mean temperature raster for 15 June 2010

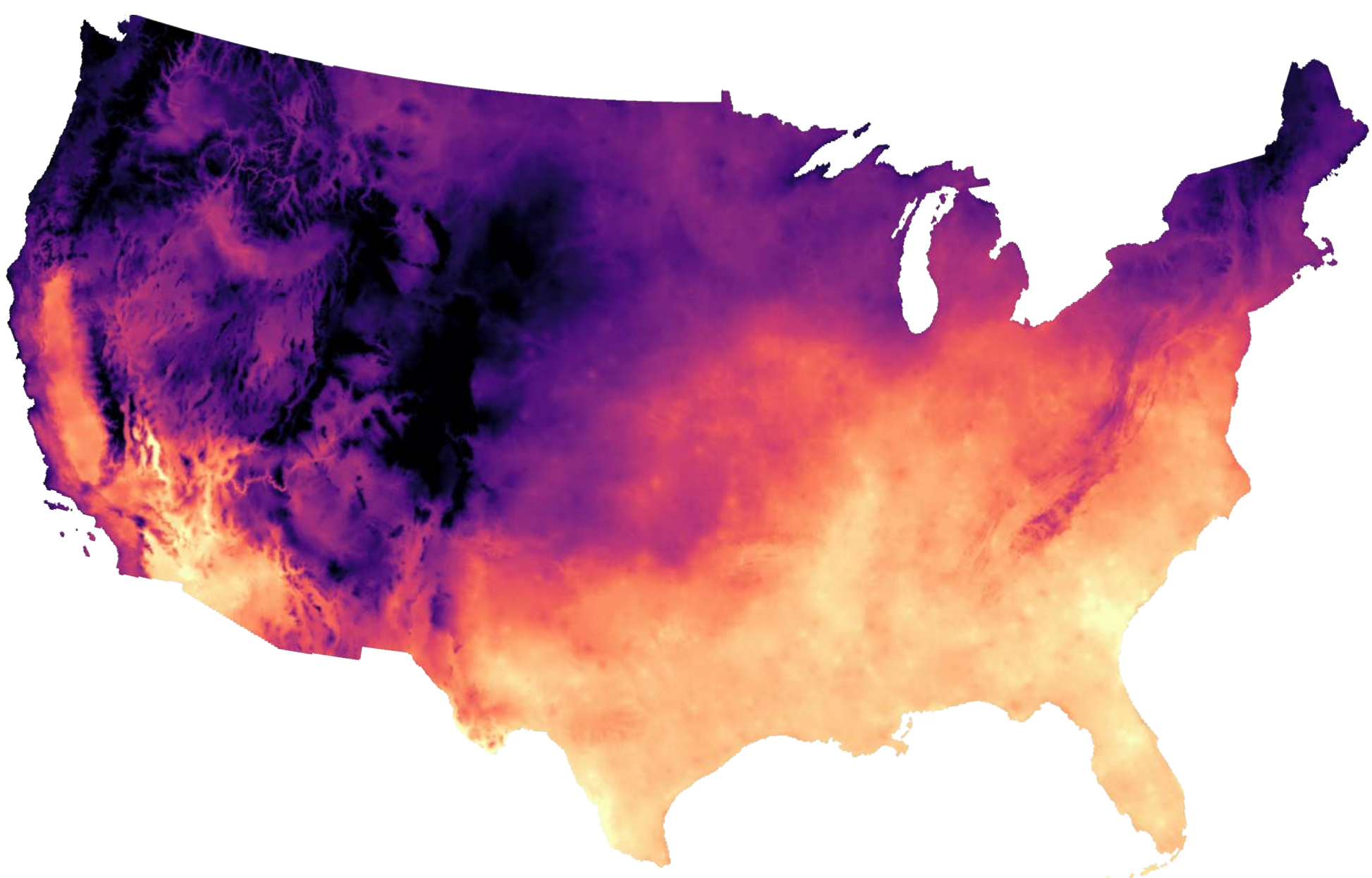

Mean temperature $\left({ }^{\circ} \mathrm{F}\right)$ 
Figure A4: Expanding the study area: Zip codes neighboring the study's zip codes

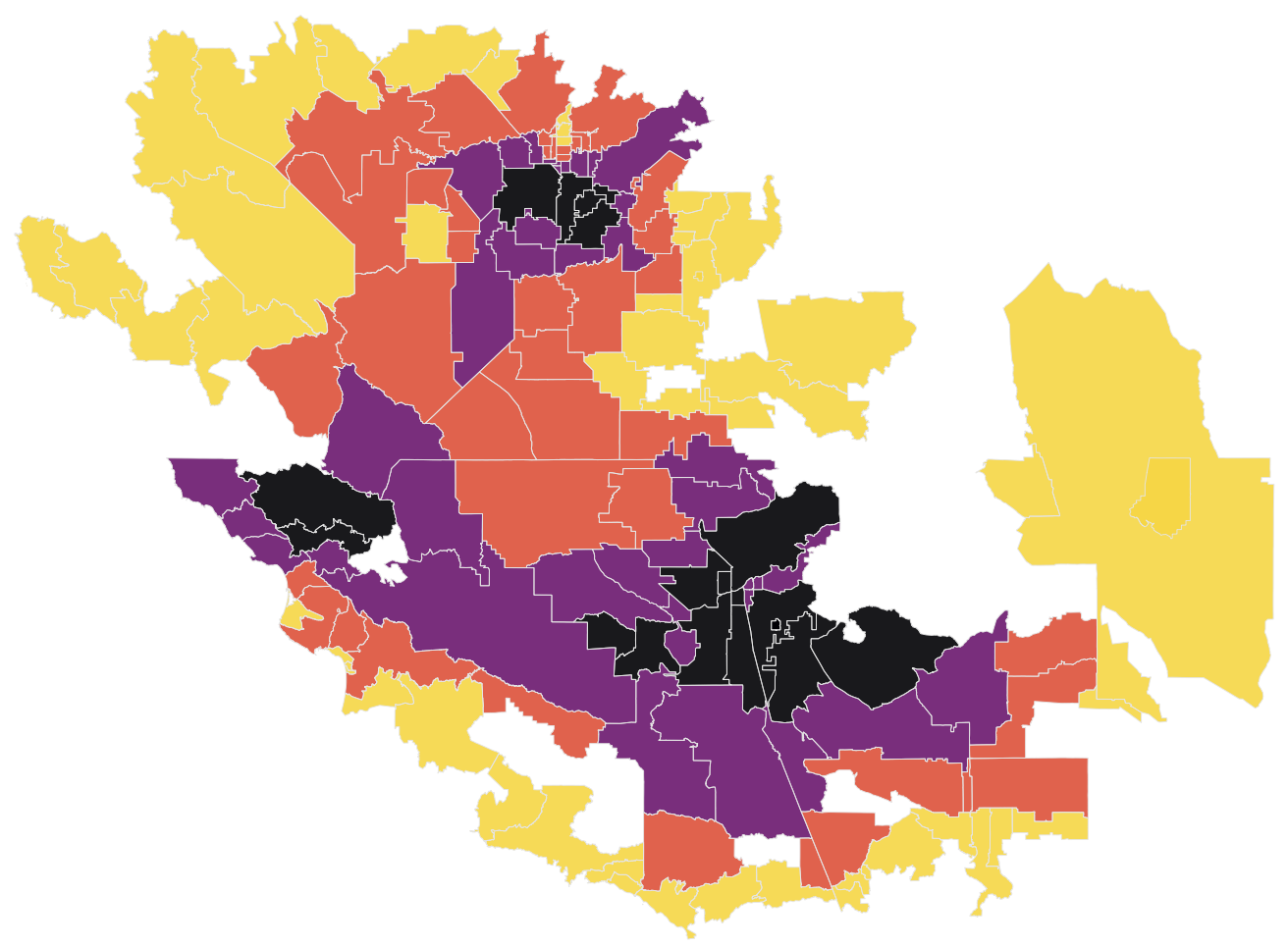

Zip-code group

Common Zips: zip codes served by both utilities

Neighbors 1: neighbors to Common Zips

Neighbors 2: neighbors to Neighbors 1

Neighbors 3: neighbors to Neighbors 2

Notes: This figure illustrates the four groups of zip codes referenced in Table A16. The groups begin with Common Zips - the group in which each zip code receives natural gas service from both PG\&E and SoCalGas_-and expands by adding each group's immediately proximate neighbors. E.g., Neighbors 2 consists of all zip codes that neighbor a zip code in Neighbors 1 (excluding those zip codes already included in another group). 


\section{A.2 Appendix tables}

Table A1: Price correlation: Bivariate correlations between types of prices

\begin{tabular}{lccccc}
\hline \hline & \multicolumn{5}{c}{ Type of Price } \\
\cline { 2 - 6 } & Marginal & Average & Avg. Mrg. & Baseline & Sim. mrg. \\
Marginal & 1 & & & & \\
Average & 0.8898 & 1 & & & \\
Avg. Mrg. & 0.8628 & 0.9421 & 1 & 1 & \\
Baseline & 0.7901 & 0.942 & 0.9202 & & \\
Sim. mrg. & 0.8503 & 0.849 & 0.8174 & 0.781 & 1 \\
\hline
\end{tabular}

Notes: Avg. or average price is the total bill divided by quantity. Avg. Mrg. or average marginal price denotes the quantity-weighted average of the household's marginal price. Base or baseline price refers to the price the household pays for its first unit (therm) of natural gas. Sim. Mrg. or simulated marginal price is the household's marginal price (using the relevant pricing regime) as a function of the household's historical consumption patterns (lagged bills 10 through 14).

Table A2: Testing the simulated instrument:

Regressing marginal price on simulated marginal price

Dependent variable: Marginal price

\begin{tabular}{lcc}
\hline \hline & $(1)$ & $(2)$ \\
\hline Simulated marginal price & $\begin{array}{c}0.6425^{* * *} \\
(0.00435)\end{array}$ & $\begin{array}{c}0.6444^{* * *} \\
(0.00433)\end{array}$ \\
\hline Bill HDDs & $\mathrm{T}$ & $\mathrm{T}$ \\
Household FE & $\mathrm{T}$ & $\mathrm{T}$ \\
City month-of-sample FE & $\mathrm{T}$ & $\mathrm{T}$ \\
Lags used for sim. inst. & $10-14$ & $11-13$ \\
$N$ & $4,892,064$ & $4,785,877$ \\
\hline
\end{tabular}

Notes: Each column denotes a separate regression. Errors are two-way clustered within (1) household and (2) utility by climate-zone by billing-cycle (the level at which price varies). All regressions include heating degree days (HDDs) within the households' billing period. Sim. Mrg. or simulated marginal price is the household's marginal price (using the relevant pricing regime) as a function of the household's historical consumption patterns (lagged bills 10 through 14 or 11 through 13). As discussed in the empirical strategy section, the numbers of observations differ due to the lags required to calculate the simulated instrument for marginal price. Significance levels: $* 10 \%, * * 5 \%, * * * 1 \%$. 
Table A3: Comparing lags, second-stage results: Marginal price with $\mathrm{HH}$ spot price IV

Dependent variable: $\log ($ Consumption, daily avg.)

\begin{tabular}{lccccc}
\hline \hline & \multicolumn{5}{c}{ Lag of Marginal Price } \\
\cline { 2 - 6 } & $(1)$ & $(2)$ & $(3)$ & $(4)$ & $(5)$ \\
& 1 Lead & No lag & $1 \mathrm{Lag}$ & 2 Lags & 3 Lags \\
\hline Log(Price) & 0.0480 & -0.1121 & -0.0223 & $-0.2098^{* * *}$ & $-0.1582^{* *}$ \\
instrumented & $(0.0902)$ & $(0.0762)$ & $(0.0668)$ & $(0.0706)$ & $(0.0698)$ \\
\hline First-stage F stat. & 326.7 & 337.9 & 410.8 & 418.4 & 403.4 \\
Bill HDDs & $\mathrm{T}$ & $\mathrm{T}$ & $\mathrm{T}$ & $\mathrm{T}$ & $\mathrm{T}$ \\
Household FE & $\mathrm{T}$ & $\mathrm{T}$ & $\mathrm{T}$ & $\mathrm{T}$ & $\mathrm{T}$ \\
City month-of-sample FE & $\mathrm{T}$ & $\mathrm{T}$ & $\mathrm{T}$ & $\mathrm{T}$ & $\mathrm{T}$ \\
$N$ & $5,501,467$ & $5,754,088$ & $5,754,088$ & $5,754,085$ & $5,754,079$ \\
\hline
\end{tabular}

Notes: With regard to lags: No lag refers to the price for the household's contemporaneous bill; 1 Lag refers to the price on the household's previous bill; etc. $(H H)$ Spot price refers to the weekly average spot price for natural gas at Louisiana's Henry Hub in the week preceding the utility's price change. Each column denotes a separate regression. Errors are two-way clustered within (1) household and (2) utility by climate-zone by billing-cycle (the level at which price varies). All regressions include heating degree days (HDDs) within the households' billing period. Significance levels: $* 10 \%, * * 5 \%, * * * 1 \%$.

Table A4: Comparing lags, second-stage results: Sim. marginal price with HH spot price IV Dependent variable: $\log ($ Consumption, daily avg.)

\begin{tabular}{lccccc}
\hline \hline & \multicolumn{5}{c}{ Lag of Simulated Marginal Price } \\
\cline { 2 - 6 } & $(1)$ & $(2)$ & $(3)$ & $(4)$ & $(5)$ \\
& 1 Lead & No lag & $1 \mathrm{Lag}$ & 2 Lags & 3 Lags \\
\hline Log(Price) & 0.0317 & -0.0549 & 0.0329 & $-0.1705^{* *}$ & $-0.1596^{* *}$ \\
& $(0.0899)$ & $(0.0718)$ & $(0.0626)$ & $(0.0698)$ & $(0.0720)$ \\
\hline First-stage F stat. & 354.7 & 379.6 & 393.2 & 369.9 & 332.1 \\
Bill HDDs & $\mathrm{T}$ & $\mathrm{T}$ & $\mathrm{T}$ & $\mathrm{T}$ & $\mathrm{T}$ \\
Household FE & $\mathrm{T}$ & $\mathrm{T}$ & $\mathrm{T}$ & $\mathrm{T}$ & $\mathrm{T}$ \\
City month-of-sample FE & $\mathrm{T}$ & $\mathrm{T}$ & $\mathrm{T}$ & $\mathrm{T}$ & $\mathrm{T}$ \\
$N$ & $4,778,382$ & $4,892,064$ & $4,785,877$ & $4,682,526$ & $4,590,790$ \\
\hline
\end{tabular}

Notes: With regard to lags: No lag refers to the price for the household's contemporaneous bill; 1 Lag refers to the price on the household's previous bill; etc. Sim. Mrg. or simulated marginal price is the household's marginal price (using the relevant pricing regime) as a function of the household's historical consumption patterns (lagged bills 10 through 14). (HH) Spot price refers to the weekly average spot price for natural gas at Louisiana's Henry $\mathrm{Hub}$ in the week preceding the utility's price change. Each column denotes a separate regression. Errors are two-way clustered within (1) household and (2) utility by climate-zone by billing-cycle (the level at which price varies). All regressions include heating degree days (HDDs) within the households' billing period. Significance levels: $* 10 \%, * * 5 \%, * * * 1 \%$. 
Table A5: Comparing lags, second-stage results: Avg. marginal price with HH spot price IV

Dependent variable: $\log ($ Consumption, daily avg.)

\begin{tabular}{lccccc}
\hline \hline & \multicolumn{5}{c}{ Lag of Average Marginal Price } \\
\cline { 2 - 6 } & $(1)$ & $(2)$ & $(3)$ & $(4)$ & $(5)$ \\
& 1 Lead & No lag & $1 \mathrm{Lag}$ & 2 Lags & 3 Lags \\
\hline Log(Price) & 0.0432 & -0.0853 & -0.0313 & $-0.1734^{* * *}$ & $-0.1356^{* *}$ \\
instrumented & $(0.0745)$ & $(0.0618)$ & $(0.0568)$ & $(0.0585)$ & $(0.0585)$ \\
\hline First-stage F stat. & 969.4 & $1,036.4$ & $1,275.3$ & $1,311.0$ & $1,306.1$ \\
Bill HDDs & $\mathrm{T}$ & $\mathrm{T}$ & $\mathrm{T}$ & $\mathrm{T}$ & $\mathrm{T}$ \\
Household FE & $\mathrm{T}$ & $\mathrm{T}$ & $\mathrm{T}$ & $\mathrm{T}$ & $\mathrm{T}$ \\
City month-of-sample FE & $\mathrm{T}$ & $\mathrm{T}$ & $\mathrm{T}$ & $\mathrm{T}$ & $\mathrm{T}$ \\
$N$ & $5,501,467$ & $5,754,088$ & $5,754,088$ & $5,754,085$ & $5,754,079$ \\
\hline
\end{tabular}

Notes: With regard to lags: No lag refers to the price for the household's contemporaneous bill; 1 Lag refers to the price on the household's previous bill; etc. Sim. Mrg. or simulated marginal price is the household's marginal price (using the relevant pricing regime) as a function of the household's historical consumption patterns (lagged bills 10 through 14). (HH) Spot price refers to the weekly average spot price for natural gas at Louisiana's Henry Hub in the week preceding the utility's price change. Each column denotes a separate regression. Errors are two-way clustered within (1) household and (2) utility by climate-zone by billing-cycle (the level at which price varies). All regressions include heating degree days (HDDs) within the households' billing period. Significance levels: $* 10 \%, * * 5 \%, * * * 1 \%$.

Table A6: Comparing lags, second-stage results: Avgerage price with $\mathrm{HH}$ spot price IV Dependent variable: $\log ($ Consumption, daily avg.)

\begin{tabular}{lccccc}
\hline \hline & \multicolumn{5}{c}{ Lag of Average Price } \\
\cline { 2 - 6 } & $(1)$ & $(2)$ & $(3)$ & $(4)$ & $(5)$ \\
& 1 Lead & No lag & $1 \mathrm{Lag}$ & 2 Lags & 3 Lags \\
\hline Log(Price) & 0.0515 & -0.1244 & -0.0177 & $-0.2312^{* * *}$ & $-0.1680^{* * *}$ \\
\cline { 2 - 6 } & $(0.0972)$ & $(0.0805)$ & $(0.0730)$ & $(0.0760)$ & $(0.0749)$ \\
\hline First-stage F stat. & 679.1 & 725.8 & 884.4 & 899.4 & 923.7 \\
Bill HDDs & $\mathrm{T}$ & $\mathrm{T}$ & $\mathrm{T}$ & $\mathrm{T}$ & $\mathrm{T}$ \\
Household FE & $\mathrm{T}$ & $\mathrm{T}$ & $\mathrm{T}$ & $\mathrm{T}$ & $\mathrm{T}$ \\
City month-of-sample FE & $\mathrm{T}$ & $\mathrm{T}$ & $\mathrm{T}$ & $\mathrm{T}$ & $\mathrm{T}$ \\
$N$ & $5,501,467$ & $5,754,088$ & $5,754,088$ & $5,754,085$ & $5,754,079$ \\
\hline
\end{tabular}

Notes: With regard to lags: No lag refers to the price for the household's contemporaneous bill; 1 Lag refers to the price on the household's previous bill; etc. Avg. or average price is the total bill divided by quantity. (HH) Spot price refers to the weekly average spot price for natural gas at Louisiana's Henry Hub in the week preceding the utility's price change. Each column denotes a separate regression. Errors are two-way clustered within (1) household and (2) utility by climate-zone by billing-cycle (the level at which price varies). All regressions include heating degree days (HDDs) within the households' billing period. Significance levels: *10\%, **5\%, ***1\%. 
Table A7: Comparing lags, second-stage results: Baseline price with $\mathrm{HH}$ spot price IV Dependent variable: $\log ($ Consumption, daily avg.)

\begin{tabular}{lccccc}
\hline \hline & \multicolumn{5}{c}{ Lag of Baseline Price } \\
\cline { 2 - 6 } & $(1)$ & $(2)$ & $(3)$ & $(4)$ & $(5)$ \\
& 1 Lead & No lag & 1 Lag & 2 Lags & 3 Lags \\
\hline Log(Price) & 0.0420 & $-0.1164^{*}$ & -0.0066 & $-0.2030^{* * *}$ & $-0.1396^{* *}$ \\
\cline { 2 - 6 } & $(0.0839)$ & $(0.0684)$ & $(0.0637)$ & $(0.0650)$ & $(0.0630)$ \\
\hline First-stage F stat. & $1,085.3$ & $1,143.4$ & $1,241.8$ & $1,333.2$ & $1,533.2$ \\
Bill HDDs & $\mathrm{T}$ & $\mathrm{T}$ & $\mathrm{T}$ & $\mathrm{T}$ & $\mathrm{T}$ \\
Household FE & $\mathrm{T}$ & $\mathrm{T}$ & $\mathrm{T}$ & $\mathrm{T}$ & $\mathrm{T}$ \\
City month-of-sample FE & $\mathrm{T}$ & $\mathrm{T}$ & $\mathrm{T}$ & $\mathrm{T}$ & $\mathrm{T}$ \\
$N$ & $5,501,467$ & $5,754,088$ & $5,754,088$ & $5,754,085$ & $5,754,079$ \\
\hline
\end{tabular}

Notes: With regard to lags: No lag refers to the price for the household's contemporaneous bill; 1 Lag refers to the price on the household's previous bill; etc. Base or baseline price refers to the price the household pays for its first unit (therm) of natural gas. (HH) Spot price refers to the weekly average spot price for natural gas at Louisiana's Henry Hub in the week preceding the utility's price change. Each column denotes a separate regression. Errors are two-way clustered within (1) household and (2) utility by climate-zone by billing-cycle (the level at which price varies). All regressions include heating degree days (HDDs) within the households' billing period. Significance levels: *10\%, **5\%, ***1\%. 
Table A8: Heterogeneity by season or income:

Second-stage results, instrumenting average price with $\mathrm{HH}$ spot price

Dependent variable: $\log ($ Consumption, daily avg.)

\begin{tabular}{|c|c|c|c|c|}
\hline & \multicolumn{4}{|c|}{ Average Price } \\
\hline & \multicolumn{2}{|c|}{ Split by Season } & \multicolumn{2}{|c|}{ Split by CARE (Income) } \\
\hline & (1) & (2) & (3) & (4) \\
\hline & Summer & Winter & CARE & Non-CARE \\
\hline $\begin{array}{l}\text { Log(Price) } \\
\quad \text { instrumented }\end{array}$ & $\begin{array}{c}0.0579^{*} \\
(0.0316)\end{array}$ & $\begin{array}{c}-0.4694^{* * *} \\
(0.1586)\end{array}$ & $\begin{array}{c}-0.2650^{* * *} \\
(0.0834)\end{array}$ & $\begin{array}{c}-0.1557^{* *} \\
(0.0740)\end{array}$ \\
\hline First-stage F stat. & 765.7 & 223.4 & 814.7 & 745.8 \\
\hline Bill HDDs & $\mathrm{T}$ & $\mathrm{T}$ & $\mathrm{T}$ & $\mathrm{T}$ \\
\hline Household FE & $\mathrm{T}$ & $\mathrm{T}$ & $\mathrm{T}$ & $\mathrm{T}$ \\
\hline City month-of-sample FE & $\mathrm{T}$ & $\mathrm{T}$ & $\mathrm{T}$ & $\mathrm{T}$ \\
\hline$N$ & $3,065,917$ & $2,688,168$ & $2,435,135$ & $3,318,950$ \\
\hline
\end{tabular}

Notes: Each column denotes a separate regression. Errors are two-way clustered within (1) household and (2) utility by climate-zone by billing-cycle (the level at which price varies). All regressions include heating degree days (HDDs) within the households' billing period. Summer includes April through September. Winter includes October through March. CARE households participate in the California Alternative Rates for Energy (CARE) program. CARE targets low-income households and provides a 20 percent discount on natural gas bills. We estimate the heterogeneity results by splitting the sample along the dimension(s) of heterogeneity and then individually estimating the models. Avg. or average price is the total bill divided by quantity. Each price in the table is the second lag of price, i.e., the prices from two bills prior to the current bill. Significance levels: * $10 \%$, $* * 5 \%, * * * 1 \%$. 
Table A9: Heterogeneity by season and income:

Second-stage results, instrumenting average price with $\mathrm{HH}$ spot price

Dependent variable: $\log ($ Consumption, daily avg.)

\begin{tabular}{lcccc}
\hline \hline & \multicolumn{4}{c}{ Average Price } \\
\cline { 2 - 5 } & $(1)$ & $(2)$ & $(3)$ & $(4)$ \\
& Summer & Summer & Winter & Winter \\
& CARE & Non-CARE & CARE & Non-CARE \\
\hline Log(Price) & 0.0495 & $0.0828^{* *}$ & $-0.6106^{* * *}$ & $-0.3971^{* *}$ \\
\multicolumn{1}{c}{ instrumented } & $(0.0384)$ & $(0.0359)$ & $(0.1570)$ & $(0.1687)$ \\
\hline First-stage F stat. & 691.5 & 591.9 & 212.7 & 184.8 \\
Bill HDDs & $\mathrm{T}$ & $\mathrm{T}$ & $\mathrm{T}$ & $\mathrm{T}$ \\
Household FE & $\mathrm{T}$ & $\mathrm{T}$ & $\mathrm{T}$ & $\mathrm{T}$ \\
City month-of-sample FE & $\mathrm{T}$ & $\mathrm{T}$ & $\mathrm{T}$ & $\mathrm{T}$ \\
$N$ & $1,293,144$ & $1,772,773$ & $1,141,991$ & $1,546,177$ \\
\hline
\end{tabular}

Notes: Each column denotes a separate regression. Errors are two-way clustered within (1) household and (2) utility by climate-zone by billing-cycle (the level at which price varies). All regressions include heating degree days (HDDs) within the households' billing period. Each price in the table is the second lag of price, i.e., the prices from two bills prior to the current bill. Summer includes April through September. Winter includes October through March. CARE households participate in the California Alternative Rates for Energy (CARE) program. CARE targets low-income households and provides a 20 percent discount on natural gas bills. We estimate the heterogeneity results by splitting the sample along the dimension(s) of heterogeneity and then individually estimating the models. Avg. or average price is the total bill divided by quantity. Each price in the table is the second lag of price, i.e., the prices from two bills prior to the current bill. Significance levels: $* 10 \%, * * 5 \%, * * * 1 \%$. 
Table A10: First-stage results:

Robustness to specification: Marginal price instrumented with spot price

Dependent variable: Log(Marginal price)

\begin{tabular}{lcccc}
\hline \hline & $(1)$ & $(2)$ & $(3)$ & $(4)$ \\
\hline Spot price & $0.3398^{* * *}$ & $0.3679^{* * *}$ & $0.3806^{* * *}$ & $0.3955^{* * *}$ \\
& $(0.0757)$ & $(0.0774)$ & $(0.0798)$ & $(0.0547)$ \\
Spot price $\times$ SoCalGas & $0.7858^{* * *}$ & $0.7868^{* * *}$ & $0.7856^{* * *}$ & $0.7385^{* * *}$ \\
& $(0.0300)$ & $(0.0299)$ & $(0.0302)$ & $(0.0378)$ \\
\hline First-stage F stat. & 416.1 & 418.4 & 415.2 & 367.0 \\
Bill HDDs & $\mathrm{F}$ & $\mathrm{T}$ & $\mathrm{T}$ & $\mathrm{T}$ \\
Household FE & $\mathrm{T}$ & $\mathrm{T}$ & $\mathrm{T}$ & $\mathrm{T}$ \\
City by month-of-sample FE & $\mathrm{T}$ & $\mathrm{T}$ & $\mathrm{F}$ & $\mathrm{F}$ \\
City by week-of-sample FE & $\mathrm{F}$ & $\mathrm{F}$ & $\mathrm{T}$ & $\mathrm{F}$ \\
Zip by week-of-sample FE & $\mathrm{F}$ & $\mathrm{F}$ & $\mathrm{F}$ & $\mathrm{T}$ \\
$N$ & $5,754,085$ & $5,754,085$ & $5,754,085$ & $5,754,085$ \\
\hline
\end{tabular}

Notes: Each column denotes a separate regression. Errors are two-way clustered within (1) household and (2) utility by climate-zone by billing-cycle (the level at which price varies). All regressions include heating degree days (HDDs) within the households' billing period. Each price in the table is the second lag of price, i.e., the prices from two bills prior to the current bill. $(\mathrm{HH})$ Spot price refers to the weekly average spot price for natural gas at Louisiana's Henry Hub in the week preceding the utility's price change. Significance levels: $* 10 \%, * * 5 \%$, $\div * * 1 \%$.

Table A11: Second-stage results:

Robustness to specification: Marginal price instrumented with spot price

Dependent variable: $\log ($ Consumption, daily avg.)

\begin{tabular}{|c|c|c|c|c|}
\hline & (1) & (2) & (3) & (4) \\
\hline $\begin{array}{l}\text { Log(Marginal price) } \\
\text { instrumented }\end{array}$ & $\begin{array}{c}-0.3623^{* * *} \\
(0.0854)\end{array}$ & $\begin{array}{c}-0.2098^{* * *} \\
(0.0706)\end{array}$ & $\begin{array}{c}-0.1705^{* * *} \\
(0.0621)\end{array}$ & $\begin{array}{c}-0.1495^{* *} \\
(0.063)\end{array}$ \\
\hline First-stage F stat. & 416.1 & 418.4 & 415.2 & 367.0 \\
\hline Bill HDDs & $\mathrm{F}$ & $\mathrm{T}$ & $\mathrm{T}$ & $\mathrm{T}$ \\
\hline Household FE & $\mathrm{T}$ & $\mathrm{T}$ & $\mathrm{T}$ & $\mathrm{T}$ \\
\hline City by month-of-sample FE & $\mathrm{T}$ & $\mathrm{T}$ & $\mathrm{F}$ & $\mathrm{F}$ \\
\hline City by week-of-sample FE & $\mathrm{F}$ & $\mathrm{F}$ & $\mathrm{T}$ & $\mathrm{F}$ \\
\hline Zip by week-of-sample FE & $\mathrm{F}$ & $\mathrm{F}$ & $\mathrm{F}$ & $\mathrm{T}$ \\
\hline$N$ & $5,754,085$ & $5,754,085$ & $5,754,085$ & $5,754,085$ \\
\hline
\end{tabular}

Notes: Each column denotes a separate regression. Errors are two-way clustered within (1) household and (2) utility by climate-zone by billing-cycle (the level at which price varies). All regressions include heating degree days (HDDs) within the households' billing period. Each price in the table is the second lag of price, i.e., the prices from two bills prior to the current bill. Significance levels: $* 10 \%, * * 5 \%, * * * 1 \%$. 
Table A12: Second-stage results:

Robustness to specification: Average price instrumented with spot price

Dependent variable: $\log ($ Consumption, daily avg.)

\begin{tabular}{lcccc}
\hline \hline & $(1)$ & $(2)$ & $(3)$ & $(4)$ \\
\hline $\begin{array}{l}\text { Log(Average price) } \\
\text { instrumented }\end{array}$ & $\begin{array}{c}-0.4076^{* * *} \\
\text { First-stage F stat. }\end{array}$ & $\begin{array}{c}-0.2312^{* * *} \\
(0.0911)\end{array}$ & $\begin{array}{c}-0.1891^{* * *} \\
(0.067)\end{array}$ & $\begin{array}{c}-0.1574^{* *} \\
(0.0656)\end{array}$ \\
Bill HDDs & 897.5 & 899.4 & 881.1 & 661.1 \\
Household FE & $\mathrm{F}$ & $\mathrm{T}$ & $\mathrm{T}$ & $\mathrm{T}$ \\
City by month-of-sample FE & $\mathrm{T}$ & $\mathrm{T}$ & $\mathrm{T}$ & $\mathrm{T}$ \\
City by week-of-sample FE & $\mathrm{T}$ & $\mathrm{T}$ & $\mathrm{F}$ & $\mathrm{F}$ \\
Zip by week-of-sample FE & $\mathrm{F}$ & $\mathrm{F}$ & $\mathrm{T}$ & $\mathrm{F}$ \\
$N$ & $5,754,085$ & $5,754,085$ & $5,754,085$ & $5,754,085$ \\
\hline
\end{tabular}

Notes: Each column denotes a separate regression. Errors are two-way clustered within (1) household and (2) utility by climate-zone by billing-cycle (the level at which price varies). All regressions include heating degree days (HDDs) within the households' billing period. Each price in the table is the second lag of price, i.e., the prices from two bills prior to the current bill. Avg. or average price is the total bill divided by quantity. Significance levels: $* 10 \%, * * 5 \%, * * * 1 \%$.

Table A13: Second-stage results:

Robustness to specification: Avg. mrg. price instrumented with spot price

Dependent variable: $\log ($ Consumption, daily avg.)

\begin{tabular}{|c|c|c|c|c|}
\hline & (1) & $(2)$ & (3) & (4) \\
\hline $\begin{array}{l}\text { Log(Avg. marginal price) } \\
\text { instrumented }\end{array}$ & $\begin{array}{c}-0.2951^{* * *} \\
(0.0697)\end{array}$ & $\begin{array}{l}-0.1734^{* * *} \\
(0.0585)\end{array}$ & $\begin{array}{c}-0.1529^{* * *} \\
(0.0514)\end{array}$ & $\begin{array}{c}-0.1330^{* *} \\
(0.0549)\end{array}$ \\
\hline First-stage F stat. & $1,299.9$ & $1,311.0$ & $1,275.8$ & 780.6 \\
\hline Bill HDDs & $\mathrm{F}$ & $\mathrm{T}$ & $\mathrm{T}$ & $\mathrm{T}$ \\
\hline Household FE & $\mathrm{T}$ & $\mathrm{T}$ & $\mathrm{T}$ & $\mathrm{T}$ \\
\hline City by month-of-sample FE & $\mathrm{T}$ & $\mathrm{T}$ & $\mathrm{F}$ & $\mathrm{F}$ \\
\hline City by week-of-sample FE & $\mathrm{F}$ & $\mathrm{F}$ & $\mathrm{T}$ & $\mathrm{F}$ \\
\hline Zip by week-of-sample FE & $\mathrm{F}$ & $\mathrm{F}$ & $\mathrm{F}$ & $\mathrm{T}$ \\
\hline$N$ & $5,754,085$ & $5,754,085$ & $5,754,085$ & $5,754,085$ \\
\hline
\end{tabular}

Notes: Each column denotes a separate regression. Errors are two-way clustered within (1) household and (2) utility by climate-zone by billing-cycle (the level at which price varies). All regressions include heating degree days (HDDs) within the households' billing period. Each price in the table is the second lag of price, i.e., the prices from two bills prior to the current bill. Avg. Mrg. or average marginal price denotes the quantity-weighted average of the household's marginal price. Significance levels: $* 10 \%, * * 5 \%, * * * 1 \%$. 
Table A14: Second-stage results:

Robustness to specification: Baseline price instrumented with spot price

Dependent variable: $\log ($ Consumption, daily avg.)

\begin{tabular}{lcccc}
\hline \hline & $(1)$ & $(2)$ & $(3)$ & $(4)$ \\
\hline $\begin{array}{l}\text { Log(Simulated mrg. price) } \\
\text { instrumented }\end{array}$ & $\begin{array}{c}-0.3148^{* * *} \\
(0.0843)\end{array}$ & $\begin{array}{c}-0.1705^{* *} \\
(0.0698)\end{array}$ & $\begin{array}{c}-0.1310^{* *} \\
(0.0602)\end{array}$ & $\begin{array}{c}-0.1025 \\
(0.0675)\end{array}$ \\
\hline First-stage F stat. & 368.9 & 369.9 & 331.3 & 181.9 \\
Bill HDDs & $\mathrm{F}$ & $\mathrm{T}$ & $\mathrm{T}$ & $\mathrm{T}$ \\
Household FE & $\mathrm{T}$ & $\mathrm{T}$ & $\mathrm{T}$ & $\mathrm{T}$ \\
City by month-of-sample FE & $\mathrm{T}$ & $\mathrm{T}$ & $\mathrm{F}$ & $\mathrm{F}$ \\
City by week-of-sample FE & $\mathrm{F}$ & $\mathrm{F}$ & $\mathrm{T}$ & $\mathrm{F}$ \\
Zip by week-of-sample FE & $\mathrm{F}$ & $\mathrm{F}$ & $\mathrm{F}$ & $\mathrm{T}$ \\
$N$ & $4,682,526$ & $4,682,526$ & $4,682,526$ & $4,682,526$ \\
\hline
\end{tabular}

Notes: Each column denotes a separate regression. Errors are two-way clustered within (1) household and (2) utility by climate-zone by billing-cycle (the level at which price varies). All regressions include heating degree days (HDDs) within the households' billing period. Each price in the table is the second lag of price, i.e., the prices from two bills prior to the current bill. Sim. Mrg. or simulated marginal price is the household's marginal price (using the relevant pricing regime) as a function of the household's historical consumption patterns (lagged bills 10 through 14 ). Significance levels: $* 10 \%$, $* * 5 \%, * * * 1 \%$.

Table A15: Second-stage results:

Robustness to specification: Baseline price instrumented with spot price

Dependent variable: $\log ($ Consumption, daily avg.)

\begin{tabular}{lcccc}
\hline \hline & $(1)$ & $(2)$ & $(3)$ & $(4)$ \\
\hline $\begin{array}{l}\text { Log(Baseline price) } \\
\text { instrumented }\end{array}$ & $-0.3643^{* * *}$ & $-0.2030^{* * *}$ & $-0.1653^{* * *}$ & $-0.1376^{* *}$ \\
\hline First-stage F stat. & $(0.077)$ & $(0.065)$ & $(0.0576)$ & $(0.0572)$ \\
Bill HDDs & $1,322.9$ & $1,333.2$ & $1,187.3$ & 762.5 \\
Household FE & $\mathrm{F}$ & $\mathrm{T}$ & $\mathrm{T}$ & $\mathrm{T}$ \\
City by month-of-sample FE & $\mathrm{T}$ & $\mathrm{T}$ & $\mathrm{T}$ & $\mathrm{T}$ \\
City by week-of-sample FE & $\mathrm{T}$ & $\mathrm{T}$ & $\mathrm{F}$ & $\mathrm{F}$ \\
Zip by week-of-sample FE & $\mathrm{F}$ & $\mathrm{F}$ & $\mathrm{T}$ & $\mathrm{F}$ \\
$N$ & $5,754,085$ & $5,754,085$ & $5,754,085$ & $5,754,085$ \\
\hline
\end{tabular}

Notes: Each column denotes a separate regression. Errors are two-way clustered within (1) household and (2) utility by climate-zone by billing-cycle (the level at which price varies). All regressions include heating degree days (HDDs) within the households' billing period. Each price in the table is the second lag of price, i.e., the prices from two bills prior to the current bill. Base or baseline price refers to the price the household pays for its first unit (therm) of natural gas. Significance levels: $* 10 \%$, $* * 5 \%, * * * 1 \%$. 
Table A16: Second-stage results: Extending the set of zip codes to neighboring zip codes Dependent variable: $\log ($ Consumption, daily avg.)

\begin{tabular}{lcccc}
\hline \hline & \multicolumn{4}{c}{ Marginal Price } \\
\cline { 2 - 5 } & Common Zips & Neighbors 1 & Neighbors 2 & Neighbors 3 \\
\hline Log(Marginal price) & $(1)$ & $(2)$ & $(3)$ & $(4)$ \\
instrumented & $-0.2098^{* * *}$ & $-0.1896^{* * *}$ & $-0.1241^{* * *}$ & $-0.0946^{* * *}$ \\
\hline First-stage F stat. & $(0.0706)$ & $(0.049)$ & $(0.0401)$ & $(0.0357)$ \\
Bill HDDs & 418.4 & 713.0 & 735.8 & $1,182.9$ \\
Household FE & $\mathrm{T}$ & $\mathrm{T}$ & $\mathrm{T}$ & $\mathrm{T}$ \\
City by month-of-sample FE & $\mathrm{T}$ & $\mathrm{T}$ & $\mathrm{T}$ & $\mathrm{T}$ \\
Levels of neighboring zip codes & $\mathrm{T}$ & $\mathrm{T}$ & $\mathrm{T}$ & $\mathrm{T}$ \\
$N$ & 0 & 1 & 2 & 3 \\
\hline
\end{tabular}

Notes: Common zips refers the set of zip codes in which each zip code receives natural gas from both PG\&E and SoCalGas. Neighbors 1 includes the common zips and the zip codes that immediately neighbor the common zips. Neighbors 2 adds the neighbors of these neighbors (adding the neighbors of Neighbors 1). Neighbors 3 adds the neighbors of Neighbors 2. Figure A4 depicts these sets of zip codes. Each column denotes a separate regression. Errors are two-way clustered within (1) household and (2) utility by climate-zone by billing-cycle (the level at which price varies). All regressions include heating degree days (HDDs) within the households' billing period. Each price in the table is the second lag of price, i.e., the prices from two bills prior to the current bill.

Significance levels: $* 10 \%, * * 5 \%, * * * 1 \%$. 
Table A17: Billing data description: Columns within the billing data

Feature name

Account ID

Premise ID

Prior read date

Current read date

Gas rate schedule

Gas usage

Bill revenue

Climate band

Service address 9-digit zip Household's 9-digit zip code

Service start date

Service stop date

\section{Description}

Unique identifier for household account with the utility

Unique physical-location based identifier

Effectively the start date of the bill

Effectively the end date of the bill

Classifies type of customer (and the customer's price regime)

Volume of gas consumed during billing period (in therms)

Total bill charged to household for the current billing period

California Public Utility Commission-based climate region

Date on which the household began service

Date on which the household ended service 


\section{A.3 Calculating bills}

As discussed in the body of the paper, the majority of bills do not line up with calendar months. Consequently, households' billing periods do not line up with utilities' monthly changes in price (or with changes in daily allowances resulting from changes in seasons). Thus, a single bill will typically span multiple price regimes. The two utilities deal with change in price in subtly different ways. This "problem" results from the fact that neither utility knows households' daily consumption.

PG\&E When a PG\&E customer's bill spans multiple calendar months (price regimes), PG\&E calculates individual bills for each month. However, because PG\&E does not know the daily consumption levels, they assume constant daily consumption throughout the billing period.

SoCalGas In the case that a SoCalGas customer's bill spans multiple calendar months (price regimes), SoCalGas computes time-weighted average prices (and allowances) by aggregating the prices and allowances from the calendar months by the number of days the bill spent in each month.

\section{A.4 Data work}

In this section, we describe the exclusion and cleaning choices that we made while preparing the data for analysis. Our R scripts are available upon request, though the data themselves cannot be shared due to agreements with the utilities and the IRB.

\section{Exclusions:}

- We omitted SoCalGas price data from advice letters 3644, 3680, 3695, 3807, 4053, and 4061, as they were updated by letters 3660, 3697, 3697, 3810, 4055, and 4069, respectively.

- We dropped pre-2008 data (PG\&E and prices/allowances), as SoCalGas did not share billing data for pre-2009 bills.

- We trimmed the shortest 2.5\% and longest 2.5\% bills (resulted in keeping bills of length between 28-34 days). We did this to omit the first or last bills for a household and bills 
that were irregular for any other reasons. We applied this requirement of 28-34 days to the current bill and the first through the third lagged bills, because we consider the effect of lagged prices on contemporaneous consumption.

- We dropped bills missing any critical information: number of therms (quantity), revenue, etc.

- We dropped bills outside the central $99 \%$ of data (i.e., the bill's revenue or volume fall in the bottom $0.5 \%$ or in the top $0.5 \%$ ). Our main results apply this rule for the contemporaneous and the first three lagged bills.

- We dropped bills whose total revenue we could not predict within five percent (using known prices, quantities, and discounts).

- We dropped bills for exactly zero therms.

CARE status While the datasets presumably denoted CARE (California Alternate Rates for Energy) households, we found many households not denoted as CARE households whose charges were consistent with CARE pricing (i.e., charges were 80 percent of the standard tariffs). We classified these households as CARE households. 